\title{
A Review of Modelling and Analysis of Morphing Wings
}

Daochun Li $i^{\mathrm{a}}$, Shiwei Zhao ${ }^{\mathrm{a}}$, Andrea Da Ronch ${ }^{\mathrm{b} *}$, Jinwu Xianga*, Jernej Drofelnik ${ }^{\mathrm{b}}$, Yongchao $\mathrm{Li}^{\mathrm{a}}$, Lu Zhang ${ }^{\mathrm{a}}$, Yining $\mathrm{Wu}^{\mathrm{a}}$, Markus Kintscher ${ }^{\mathrm{c}}$, Hans Peter Monner ${ }^{\mathrm{c}}$, Anton Rudenko ${ }^{\mathrm{c}}$, Shijun Guo ${ }^{\mathrm{d}}$, Weilong Yin $^{\mathrm{e}}$, Johannes Kirn ${ }^{\mathrm{f}}$, Stefan Storm ${ }^{\mathrm{f}}$, Roeland De Breukerg,

a School of Aeronautic Science and Engineering Beihang University, Beijing, China

${ }^{\mathrm{b}}$ Faculty of Engineering and the Environment University of Southampton, Southampton, SO17 1BJ, UK

${ }^{\mathrm{c}}$ Institute of Composite Structures and Adaptive Systems German Aerospace Centre, Braunschweig, Germany

${ }^{\mathrm{d}}$ Aerospace Engineering, School of Engineering Cranfield University, Bedford, UK

${ }^{\mathrm{e}}$ College of Aeronautics Harbin Institute of Technology, Harbin, China

${ }^{\mathrm{f}}$ IC3 - Energy, Propulsion \& Aerodynamics, Airbus Group Innovations Munich, Germany

${ }^{g}$ Aerospace Structures and Computational Mechanics, Delft University of Technology Delft, The Netherlands

\begin{abstract}
Morphing wings have a large potential to improve the overall aircraft performances, in a way like natural flyers do. By adapting or optimising dynamically the shape to various flight conditions, there are yet many unexplored opportunities beyond current proof-of-concept demonstrations. This review discusses the most prominent examples of morphing concepts with applications to two and threedimensional wing models. Methods and tools commonly deployed for the design and analysis of these concepts are discussed, ranging from structural to aerodynamic analyses, and from control to optimisation aspects. Throughout the review process, it became apparent that the adoption of morphing concepts for routine use on aerial vehicles is still scarce, and some reasons holding back their integration for industrial use are given. Finally, promising concepts for future use are identified.
\end{abstract}

Keywords: morphing wings; unmanned aerial vehicles; concepts; demonstrators; methods 


\section{Table of Contents}

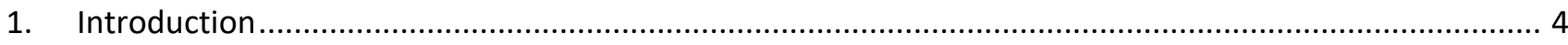

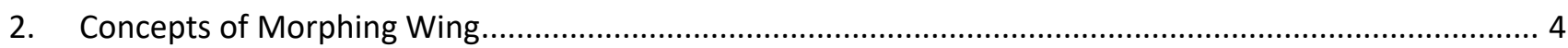

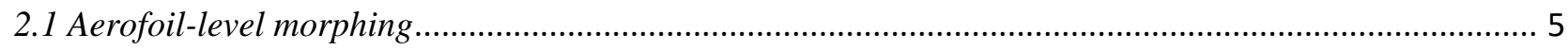

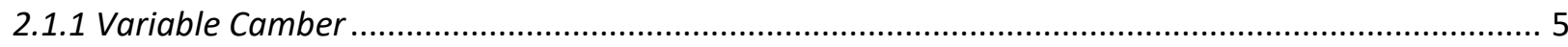

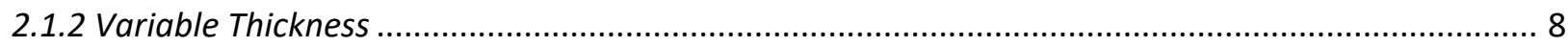

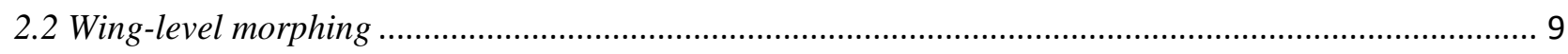

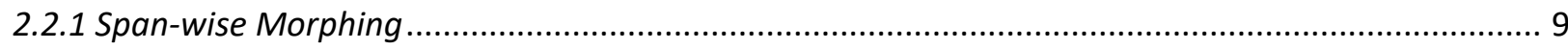

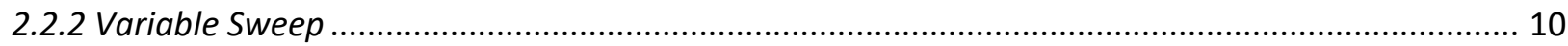

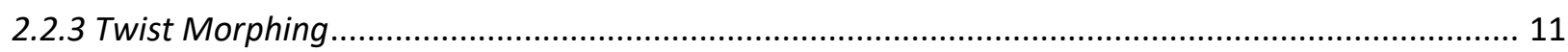

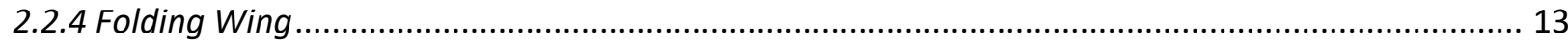

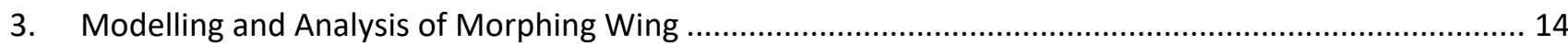

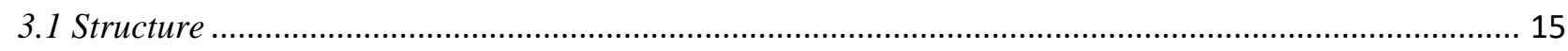

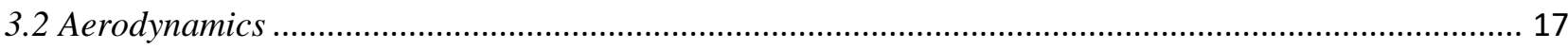

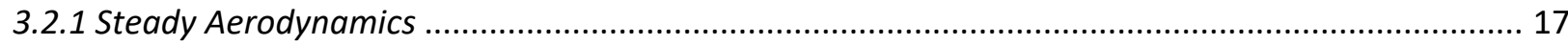

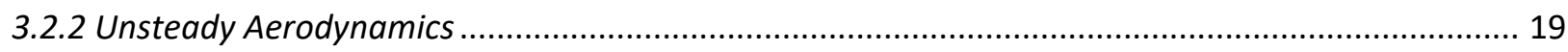

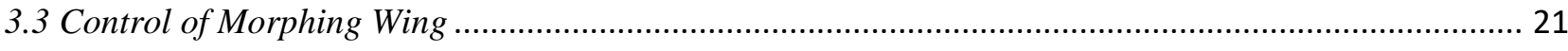

3.3.1 Transformation Between Different States............................................................................... 21

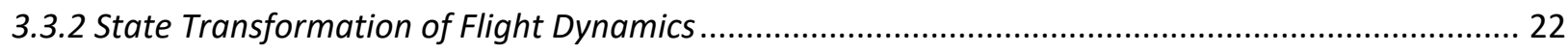

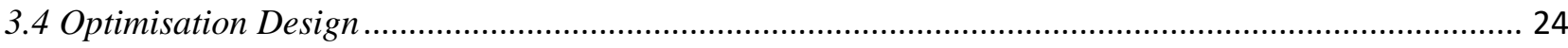

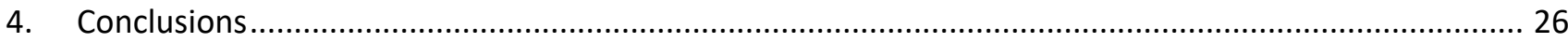

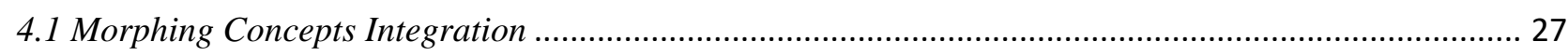

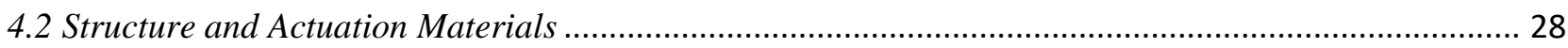

4.3 Modelling and Analysis Methods ………………........................................................................ 28

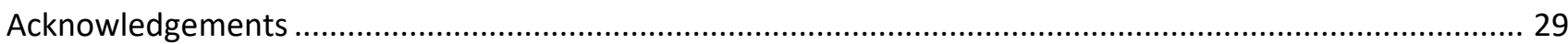

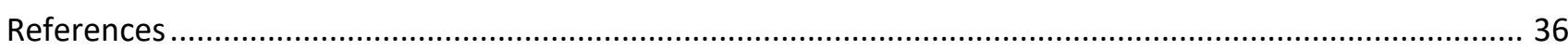




\begin{tabular}{|l|l|}
\hline \multicolumn{2}{|c|}{ Nomenclature } \\
\hline Symbols & Lift coefficient \\
\hline$C_{L}$ & Drag coefficient \\
\hline$C_{D}$ & \\
\hline Subscripts & \\
\hline & Two-dimensional \\
\hline Acronyms & Three-dimensional \\
\hline 2D & European Commission \\
\hline 3D & Computational fluid dynamics \\
\hline EC & Doublet lattice method \\
\hline CFD & European Commission \\
\hline DLM & Finite element method \\
\hline EC & Framework Programme \\
\hline FEM & Immune genetic algorithm \\
\hline FP & Limit-cycle oscillation \\
\hline IGA & Population-based incremental learning \\
\hline LCO & Polydimethylsiloxane \\
\hline PBIL & Proportional, integral, derivative \\
\hline PDMS & Polylactide \\
\hline PID & Micro Air Vehicle \\
\hline PLA & Novel Air Vehicle Configurations: From Fluttering Wings to Morphing Flight \\
\hline MAV & Reynolds-averaged Navier-Stokes \\
\hline NOVEMOR & Radar cross section \\
\hline RANS & Reduced order method \\
\hline RCS & Smart High Lift Devices for Next Generation Wings \\
\hline ROM & Smart Intelligent Aircraft Structures \\
\hline SADE & Shape Memory Alloy \\
\hline SARISTU & Solid Isotropic Material with Penalization \\
\hline SMA & Tensor product \\
\hline SIMP & Technology readiness level \\
\hline TP & Unmanned aerial vehicle \\
\hline TRL & Vortex lattice method \\
\hline UAV & \\
\hline VLM & \\
\hline
\end{tabular}




\section{Introduction}

The word morph derives from the Greek word 'morphos', which means shape. In today’s meaning, morph indicates the ability to transform shape or structure. The majority of the references reviewed in this article emulates biological structures and functions. During flight, aircraft fly at different flight conditions with corresponding targets and requirements. Consider, for example, the take-off and cruise phases of flight. The overarching idea of a morphing wing is to adapt its aerodynamic shape to each flight condition to obtain better performances, such as flight envelope, flight control, flight range. The cost and complexity of design, manufacture and maintenance can also be decreased by replacing specific mission tailored aircraft designs with a single type of morphing aircraft. The largest economic driver is having a fleet of a single morphing aircraft capable of being utilized on different mission objectives and flight conditions, as opposed to a fleet of several aircraft types, each designed for a specific mission objective and function.

A large body of work on morphing structures exists, and is based either on material or shape morphing mechanisms [1-12]. Some of these references classified morphing wings based on the geometry change [1-3, [9] or the actuator concepts [7], while other references focused at one specific element, such as special materials and relative techniques [6,8,11,12], special actuators [10] and applications [4,5]. As documented in these references (and references therein), it is apparent that considerable progress on morphing wings has been made. It is believed that this was made possible by the increased sophistication of methods and tools deployed in the design and analysis phases, as well as continued efforts in wind tunnel and flight experimentation.

The present review is intended to identify the modelling and analysis methods (structure, aerodynamics, aeroelasticity, control and optimization) with applications on morphing wings, and to provide an alternative reasoning to categorize morphing concepts. In relation to projects funded by the European Commission (EC), an overview of the following projects is contained herein: Smart High Lift Devices for Next Generation Wings (SADE) project supported under the Seventh Framework Programme (FP) of the EC (2008 - 2012, website: http://www.sade-project.eu/); Smart Intelligent Aircraft Structures (SARISTU) project under the Seventh FP of the EC (2011 - 2015, http://www.saristu.eu/); and Novel Air Vehicle Configurations: From Fluttering Wings to Morphing Flight (NOVEMOR) project (2011 - 2014).

\section{Concepts of Morphing Wing}

We start reviewing morphing concepts that are applied to aerofoil-level morphing (2D) and winglevel morphing (3D) wing configurations. In Section 2.1, concepts concerning variable camber and thickness are discussed for 2D test cases. Aerofoil morphing affects the aerofoil shape of a wing that 
alters local aerodynamics to improve lateral stability and manoeuvrability, while reducing air resistance (drag). The extension to 3D configurations is done in Section 2.2 that contains concepts such as span and twist morphing, variable sweep angle and wing folding mechanisms. Wing-level morphing affects the entire shape of the wing. It alters the twist, sweep, dihedral and span of the wing to optimise the wing shape for different scenarios, such as take-off, cruise and landing.

The time evolution of morphing wing concepts is summarised in Table 1 . Therein, the list is limited to references that resulted in physical prototypes only, i.e. technology readiness level (TRL, which represents the evolution of an idea from a thought to the full deployment of a product in the marketplace) 3-4 or higher. Wind tunnel and flight tests represent TRL 5-6 and TRL 7-9, respectively. Most concepts have achieved TRL 5 (30 out of 41 in Table 1), and fewer concepts have achieved TRL 7 (10 out of 41 in Table 1).

Table 2 maps the development of specific morphing concepts to design problems, highlighting the multitude of design solutions developed in response to common design drivers (performance, flight control, etc.). Morphing concepts are classified into three morphing levels: low, medium, and high. The higher the morphing level, the larger the weight introduced by the morphing concept. Herein, the highest achievable performances of the morphing wings are compared with conventional wings. The 2D morphing concepts are easier to manufacture and to assemble compared to 3D morphing concepts, since only a fraction of the wing is subjected to design modifications. Moreover, the 2D morphing concepts promise higher reliability compared to 3D concepts, as the morphing device is not the main load-bearing structure of the morphing wing.

\subsection{Aerofoil-level morphing}

\subsubsection{Variable Camber}

Varying the camber of a wing may have beneficial properties for controlling the aerial vehicle during, for example, the take-off and landing phases of flight. This will, in turn, modify the lift distribution along a wing. Most of the morphing concepts intended for 2D configurations, although varied in their implementation, operate to modify the camber. The variation of the wing camber may occur locally, as for the case of changes at the leading or trailing-edge, or globally, whereby the entire wing acts as a single control effector.

\section{Morphing Leading-edge}

In a conventional high-lift configuration, slats are deployed to achieve a higher lift coefficient than achievable for a clean wing configuration. However, it is well-known that slat gaps at the 
leading-edge are the dominant source of airframe noise during approach. A morphing leading-edge is intended to not only reduce the noise but also promote the flow to be laminar, in turn reducing drag.

The aim of the SADE project was to investigate the design, manufacturing, and ground testing of a smart leading-edge device. Figure 1 shows the SADE Smart Droop-nose Wind tunnel test. Together with Airbus Group Innovations, a lightweight integrated approach for highly anisotropic skins combined with kinematics and actuators was investigated to realise a gapless droop-nose [17]. A fullscale 3D wing segment was tested. The good agreement of the experimental results and simulations indicated a feasible concept and design method. The identified deviations from the targeted shape were attributed to manufacturing tolerances [18][19].

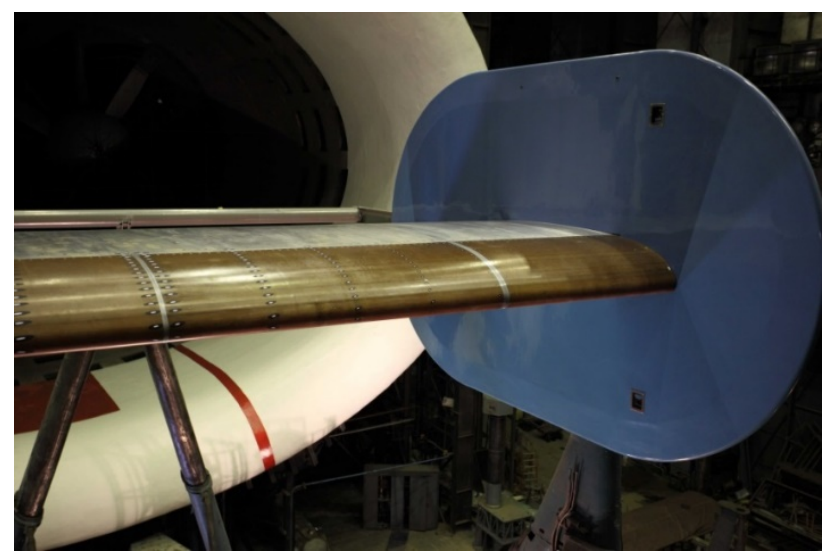

Figure 1: Smart droop-nose wind tunnel testing performed within the SADE project [17]

The SADE project focused on the structural challenge of realizing morphing high-lift devices for given aerodynamic target shapes. At the end of the project, the TRL of the smart droop-nose was increased from 1 to 4 . The aim of the SADE project was to build high-lift performance morphing wing devices, competitive with conventional high-lift devices, and with significantly reduced complexity and mass. A realistic full scale 2D section of a morphing wing was manufactured and tested in the TsAGI T-101 wind tunnel. Results of ground tests and low-speed wind tunnel tests indicated sufficient stiffness under aerodynamic loads and good shape accuracy [19]-[21].

The integration of required technologies for applications to aircraft wings were investigated in the follow-up EC-funded SARISTU project, which included the integration of anti/de-icing functionality, erosion protection, impact protection, bird strike protection and lightning strike protection. The small design space and large curvature at the wing leading-edge, combined with the small chord length, represented a design challenge [22][23]. The successful integration of additional functionalities, e.g. de-icing, erosion protection and lightning strike protection, was demonstrated by simulations, ground tests which included wing bending and fatigue tests, and a low-speed wind tunnel test [24]-[26].

The combination of a morphing droop-nose and inner mechanism derived by topology 
optimisation was applied to a winglet leading-edge in the NOVEMOR project. A morphing leadingedge model was designed and manufactured as an intermediary step in preparation for wind tunnel testing of a droop-nose adaptive morphing wingtip [27]. The model featured a flexible fiberglass skin, a monolithic aluminium internal compliant mechanism and support structure for lightweight design. The design process involved the design of the skin using a structural optimisation tool, followed by continuum gradient-based topology optimisation of the compliant mechanism first, and then of the support structure [28]. A successful wind tunnel test was conducted, where the structural stiffness under aerodynamic loads was tested [29].

\section{Morphing Trailing-edge}

The objective of the flexible trailing-edge is to achieve a chord-wise and span-wise differential camber variation with the same structural system providing a smooth contour with no additional gaps. The camber variation is localised at the trailing-edge because this region has high effectiveness under both aerodynamic and structural viewpoints. Consider, for example, that flaps (e.g. fowler flaps) and ailerons of civil transport aircraft are positioned in this region. It was therefore important to develop a cambering system that could be used to complement the fowler flaps by additional cambering function, which was able to act as a substitution of the ailerons.

The finger concept substitutes the inflexible ribs of a conventional flap by ribs of a flexible design. Therefore, the skin fields must be able to glide on the flexible ribs to ensure a suitable deformation without buckling. To avoid intolerable large strain, it was necessary to separate the upper and lower skins in the span-wise direction. The basic design of the flap front part is almost unchanged to avoid a totally new design concept for the fixed part section. Figure 2 shows the design of the flexible trailing-edge with the deformable ribs [30].

The flexible ribs were realised by combining separate plate-like elements with revolute joints. Due to such construction, the design is called “Finger Concept”. In Figure 2, a single actuator per rib is necessary to deform the rib up or downward. However, by using a transmission beam it is possible to cluster ribs so that two actuators drive five ribs, reducing the number of the actuators significantly. The rotation of the driven element is transferred gradually from element to element by kinematics, allowing the desired rib contour to gain a span-wise constant and differential cambering and decambering. The length of the rib elements determines the shape of the deformed rib, obtaining an arc or elastic line-like shape of a beam. 


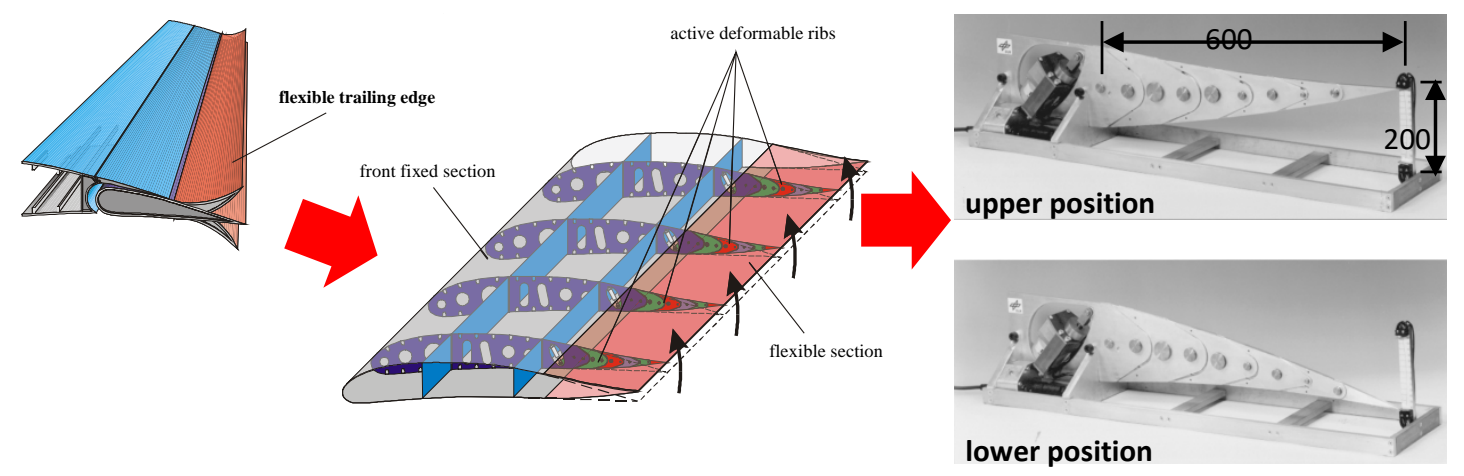

Figure 2: Position and design of active deformable ribs in the Fowler flap [30]

In the Belt-Rib concept, it is not necessary to separate the upper and lower skins from each other. A closed belt transfers the actuator stroke into a camber variation of the aerofoil. The upper and lower parts of the belt are connected by spokes, as seen in Figure 3. Changing the angle of the spokes in the un-deformed rib, changes the contour of the deformed trailing-edge. Using this concept, it is possible to obtain a span-wise constant and variable cambering. Due to the closed belt of the skin, the front part of the rib deforms upward when the rear part is deformed downward, and vice versa. With a smart layout of the spokes and the belt, it is possible to minimise this effect but not to remove it entirely.
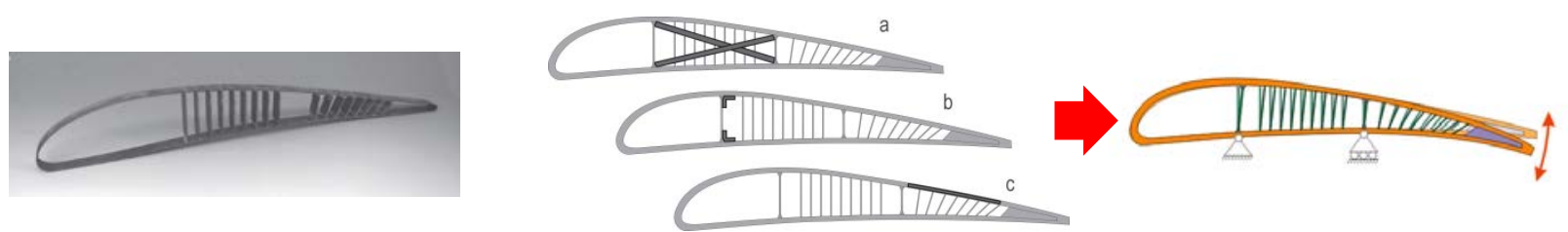

Figure 3: Belt-Rib concept showing demonstrator (left), activation (centre) and deformation (right) [31]

\subsubsection{Variable Thickness}

Drag reduction may be achieved by modification of the aerofoil thickness which has a direct effect on the location of the laminar-to-turbulent flow transition. The main design driver is to promote large laminar regions on the wing surface by delaying the transition location towards the trailing-edge. Figure 4 shows a variable thickness and variable camber aerofoil that includes a flexible skin installed on the upper wing surface and the shape memory alloy (SMA) actuator system. The actuators were composed of two oblique cams that converted the horizontal movement along the span into vertical motion perpendicular to the chord. The pulling action of the gas spring retracted the flexible skin in the un-deformed reference aerofoil position, while the pulling action of the SMA wires deployed the actuators in the load mode, i.e. morphed aerofoil in the optimized aerofoil position [32]. It was observed that the open loop method exhibited higher fidelity of the imposed aerofoil shape and was more accurate in terms of aerodynamic results. The closed loop method has 
the advantage to reproduce the load distribution that can vary over time [33]-[38]. Reference [39] built an aero-structural model which was used to minimise the drag force under constant-lift conditions during the wind-tunnel testing using a two-step optimisation algorithm (global and local search). In [40], a wind tunnel test of a real-time optimisation of a morphing wing to delay the transition towards the trailing-edge was documented.

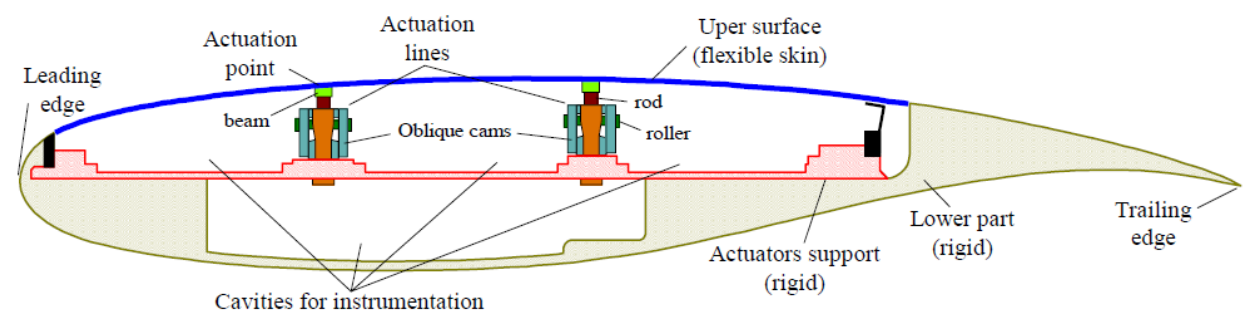

Figure 4: Cross section of a variable thickness morphing wing model [33]

\subsection{Wing-level morphing}

\subsubsection{Span-wise Morphing}

Fixed high aspect-ratio wings have an advantage in fuel efficiency, but lack manoeuvrability and operate at relatively low cruise speeds. On the contrary, aircraft with low-aspect ratio wings are faster and have better manoeuvrability, but show poor aerodynamic efficiency. A variable-span wing has potential to leverage on the advantages of each configuration. Aircraft with span morphing wings have been built and flown in the past, as graphically reported in Figure 5.

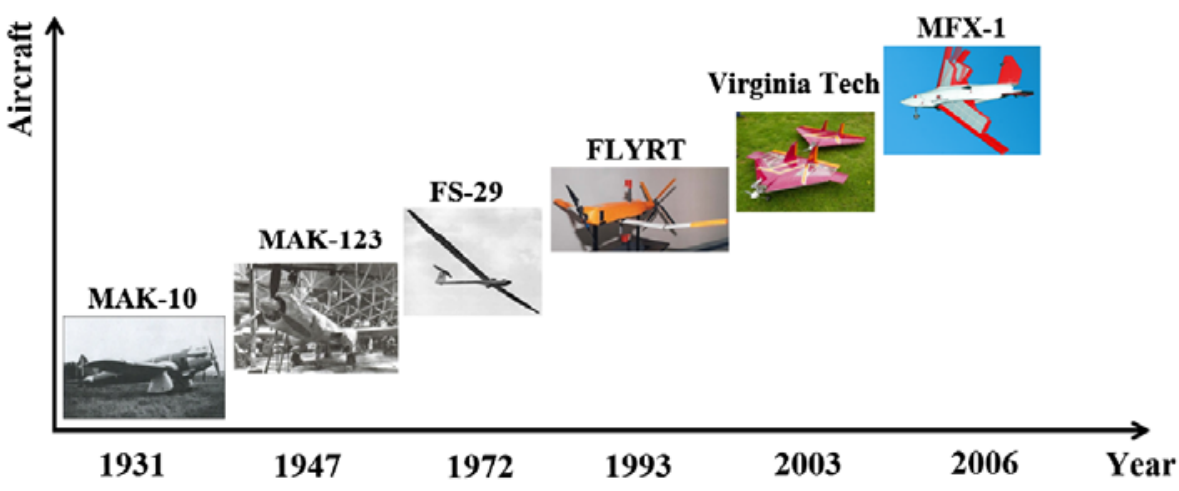

Figure 5: Aircraft with span morphing wing [41]

The variable-span concept is also applied in rotary-wing aircraft, and shows similar advantages as fixed wings. For stowed rotors, the concept alleviated dynamic and strength problems associated when stopping the rotor during flight, while for compound helicopters this concept reduced drag at high forward speeds. This concept offers some solutions to the technical problems of large civil tilt rotors. The rotors could change diameter in flight, so that a large diameter (helicopter size) rotor is used in hover and a smaller diameter (propeller size) rotor is used in cruise. 
Reference [42] presented an aero-structural design and analysis study of a telescopic wing with a conformal camber morphing capability. The telescoping wing can continuously change the wing span by having an inner wing that slides in and out of the outer wing. The structural solution adapted to achieve the variable span capability consists of a hollow outer wing, which supports loadings by having leading and trailing-edge composite carbon fibre reinforcement, as well as composite carbon fibre reinforcements, evenly spaced along the span to substitute conventional ribs. References [43] and [44] described the implementation of a continuous span morphing wing with two primary components: 1) zero-Poisson ratio morphing core; and 2) fibre-reinforced elastomeric matrix composite skin with a nearly-zero in-plane Poisson ratio. Wind tunnel tests showed that the novel morphing system could increase span by $100 \%$ while maintaining a constant chord, with a maximum out-of-plane deflection of less than $2.54 \mathrm{~mm}$. Reference [45] developed a variable-span morphing wing model tested in a wind tunnel. Experimental results demonstrated an improvement in the aerodynamic efficiency, showing reduced drag and a subsequent increase of $5 \%$ in flight range and $17 \%$ in endurance. In [46], the compliant spar concept was developed and modelled to allow the wingspan to be varied, providing roll control and enhancing the operational performance for a medium altitude long endurance unmanned aerial vehicle (UAV). The compliant spar is made of compliant joints arranged in series to allow the partition to be flexible under span-wise loads, yet stiff enough to resist bending loads. Reference [46] developed a novel span morphing concept, referred to as the gear driven autonomous twin spar (GNATSpar), for a mini-UAV. The GNATSpar can be used to achieve span extensions up to $20 \%$ to reduce induced drag and increase flight endurance. Reference [47] presented the Zigzag wing box concept that allows the wing span to be varied by $44 \%$ (22\% extension and $22 \%$ retraction). The Zigzag wing box consists of a rigid part and a morphing part. The rigid part is a semi-monocoque construction that houses the fuel tank, and transfers the aerodynamic loads from the morphing part to the fuselage.

\subsubsection{Variable Sweep}

The concept of variable sweep wing was adopted for military fighter aircraft from the 1950s, primarily to achieve higher supersonic cruising speeds. The first production aircraft with sweep wing capability was the F-111. Many military aircraft appeared with variable-sweep wings during the 1960s and 1970s, including the Panavia Tornado, the Mikoyan Mig-23, the Shukoi Su-22, the Su-24, and the Tupolev Tu-160 Blackjack.

Recent studies have focused on micro air vehicle (MAV) and UAVs, which are mostly bioinspired. RoboSwift, as shown in Figure 6(a), is a morphing wing based on discrete feather-like elements inspired by swift birds [48]. The wing can fold its feathers backwards, thereby changing its wing sweep. Aerial robots, capable of locomotion in both air and water, would enable novel mission 
profiles in complex environments, such as water sampling after floods or underwater structural inspections. Aquatic Micro Air Vehicle (AquaMAV) in Figure 6(b) is designed to satisfy such mission profiles, and uses a reconfigurable wing to dive into the water from flight. This vehicle concept was inspired by the plunge diving strategy of water diving birds in the family Sulidae [49].
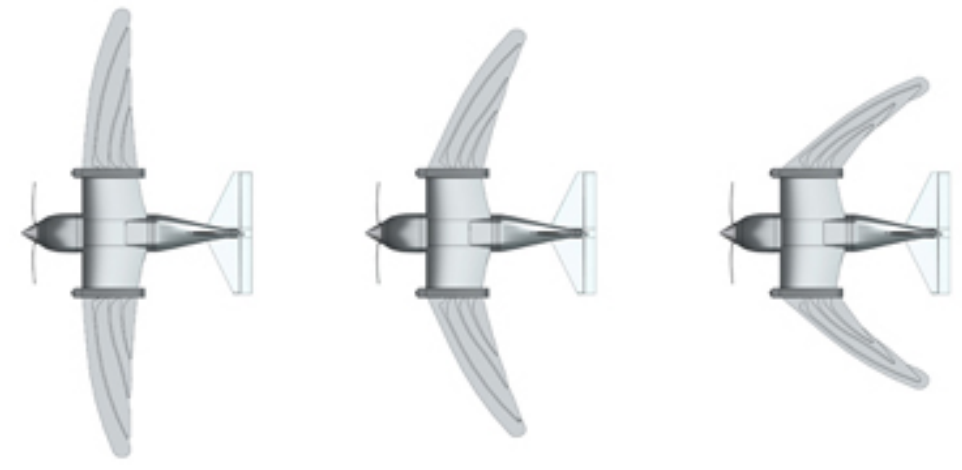

(a) RoboSwift inspired by swift birds [48]

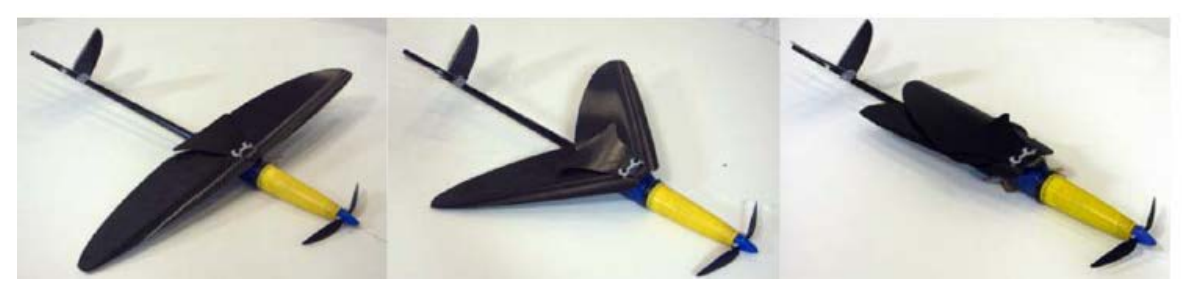

(b) AquaMAV airframe inspired by Sulidae birds [49]

\section{Figure 6: Bioinspired variable sweep wing}

The influence of variable-sweep wing on the aircraft radar cross section (RCS) characteristics was studied to reduce the aircraft RCS, as well as its detection probability by the hostile radar [50]. Results indicated that for a leading-edge sweep angle of 33 deg, the arithmetic average of the RCS values in the head direction of the aircraft is $0.644 \%$ of the average value at sweep angle of 0 deg. References [51] presented the dynamic response of variable sweep wing aircraft, demonstrating that the variable sweep wing aircraft can control pitch, when left and right-wing sweeps are symmetric. Reference [52] presented a design study of a supersonic business jet with variable sweep wings. In the subsonic/low-speed position, the movable wing panels feature a 35 deg leading-edge sweepback, whereas in the supersonic regime, they feature a 60 deg sweepback that results in fully subsonic flow at the leading-edge during Mach 1.6 cruise.

\subsubsection{Twist Morphing}

By twisting the wing and inducing 'wash-in' and 'wash-out', the lift distribution along the span of the wing can be manipulated. Varying the twist distribution of the wing to enhance flight performance and control authority of the air vehicle may be regarded as the oldest form of morphing. 
The Wright brothers employed the wing warping technique to change the twist of a flexible wing and to provide roll control for their first flying machine. However, the quest for enhanced performance and higher airspeed required stiff structures to avoid aeroelastic instabilities and to meet loading requirements. This trend increased the structural weight of the vehicle and penalised its performance.

The twisted morphing can produce a significant impact on the aerodynamic behaviour of a lifting surface without the need for large platform modifications, such as those associated with variable sweep or span that usually require complex and heavy mechanisms. In addition, twist morphing (e.g. camber morphing) can serve multiple tasks simultaneously, such as to alleviate gust and manoeuvre loads, increase the lift coefficient, and replace conventional control surfaces. Various actuation methods ranging from SMA, piezoelectric and others have been investigated for twist morphing. A modular and reversibly assembled wing that performs continuous span-wise twist deformation was developed in Ref. [53]. Tip twist actuation is achieved using a flexure arm. The geometry of the arm in relation to the actuation source (servo motor) and the end effector (torque tube) achieves a favourable torque ratio, as shown in Figure 7.

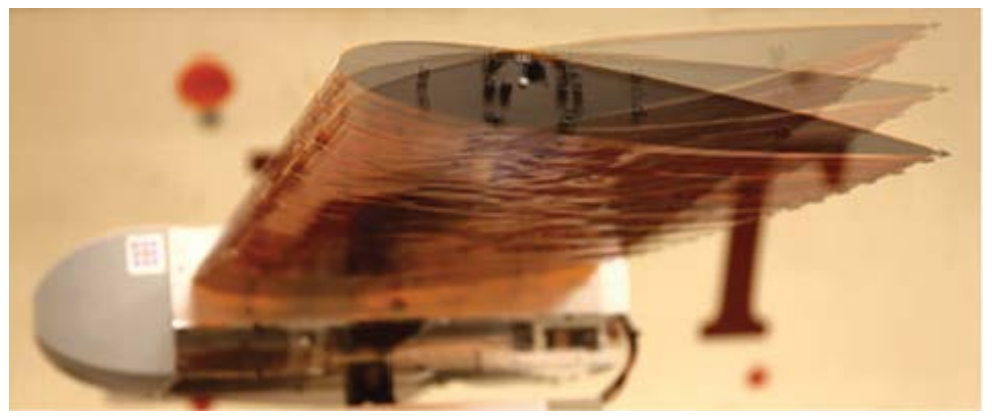

Figure 7: Wind tunnel twist of the modular and reversibly assembled wing [53]

Reference [53] performed an aerodynamic design optimisation of a MAV wing to obtain the optimal anti-symmetric wing twist distribution for the roll control of the MAV wing instead of using conventional ailerons. The purpose was to produce minimum induced drag and to achieve a better roll response, using feasible directions gradient based optimisation algorithms, implemented in the optimisation system. Reference [55] performed a lift-to-drag optimisation on twisted morphing wing to obtain the optimal condition for the morphing wing configuration. Two-way fluid structure interaction simulations and wind tunnel testing were used to solve and study the basic wing aerodynamic performance over (non-optimal) twisted morphing, membrane and rigid wings. Then, a multi-fidelity metamodel-based design optimisation process was adopted to maximise the aerodynamic efficiency using Ansys Design Xplorer. In [56], a new concept for actively controlling wing twist was reported. The concept relied on introducing warping deformation of the wing skin, which was split at the trailing-edge to create an open-section aerofoil. It was demonstrated that at lower angles of attack, a more positive twist resulted in a higher lift-to-drag ratio. The study proved that a twist-active wing can have sufficient gain to control the rolling motion of an aircraft and to 
ensure that the lift-to-drag ratio is maximised at various flight conditions. Hugo et al [57] presented a novel concept for a twist morphing wing segment, where only a segment of the wing is actuated, causing rotation of the tip of the wing, while the base segment is fixed. The morphing segment consists of a smart soft composite structure made from polydimethylsiloxane (PDMS) and polylactide (PLA), which is actuated by multiple embedded SMA wires. This structure was implemented in a UAV-sized wing and was tested both in still-air conditions and in an open-type wind tunnel to determine the actual impact of this mode of actuation. Wolfram et al [58] presented a novel semi-passive morphing aerofoil concept based on variable bending-twist coupling, induced by adaptive shear centre location and torsional stiffness. Results showed that the concept relying on smart materials allows effective twist control, while offering the potential of reduced weight and better energy efficiency.

\subsubsection{Folding Wing}

The folding wing configuration is a strong candidate for morphing wing design that changes the wing area, in turn affecting various aspects of flight such as climb rate, stall characteristics, and lateral stability. Folding wing is another bio-inspired concept, mimicking either bats or bird's feathers. While there are many differences between flying animals and flying robots, a prominent one is that natural flyers are capable of wing folding during flight. Bats use an articulated skeleton covered by an elastic membrane under active muscular control to morph their wings, but wing folding is limited by membrane slacking. In contrast, birds can morph their wings until they are tucked against the body, while maintaining a high performance aerodynamic shape, due to overlapping feathers under musculoskeletal control. Further, extreme morphing allows pigeons and swifts [59] to increase efficiency by adjusting wing span while flying at a wide range of speeds to take advantage of optimum glide conditions.

Lockheed Martin folding wing aircraft could achieve a 200\% wing area change. Josh et al [60] presented an experimental investigation on using folding wingtips serving as control effectors for a mini UAV. Both static (longitudinal and lateral) and dynamic (longitudinal) wind tunnel tests were conducted. Results showed that folding wingtips are effective (especially at large dynamic pressures and angles of attack) in controlling the lateral and directional stability. Ma et al [61] proposed an active morphing wing to imitate the motion of bats. The pericardial folding and stretching of the wing is driven by a cam installed on the crank shaft. The cam contour influences the flapping trajectory, which affects the aerodynamic force of the wing. Wang et al [62] presented a general structural dynamics model that predicts the natural frequencies of a folding wing with simplified geometry but with an arbitrary number of wing segments. Three experimental models were constructed, and the natural frequencies were measured over a wide range of fold angles. A novel 
morphing wing design composed of artificial feathers that can rapidly modify their geometry to fulfil different aerodynamic requirements is introduced in [63], as shown in Figure 8. Results show that a fully deployed configuration enhances manoeuvrability, while a folded configuration offers low drag at high speeds, and is beneficial in strong headwinds.

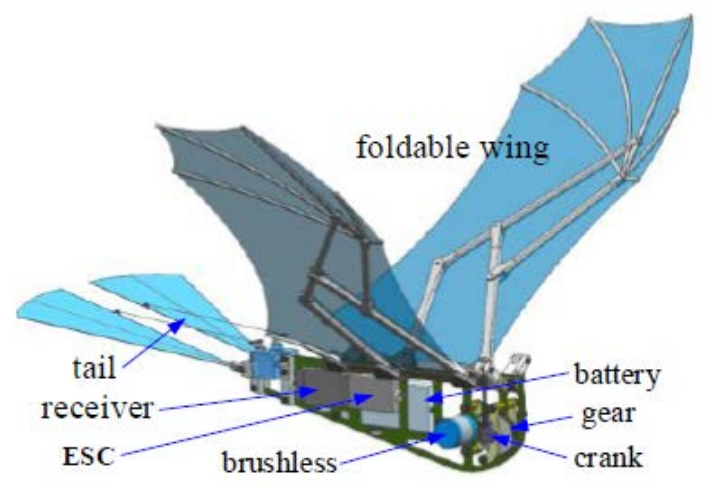

(a) Bioinspired bat-like robot [61]
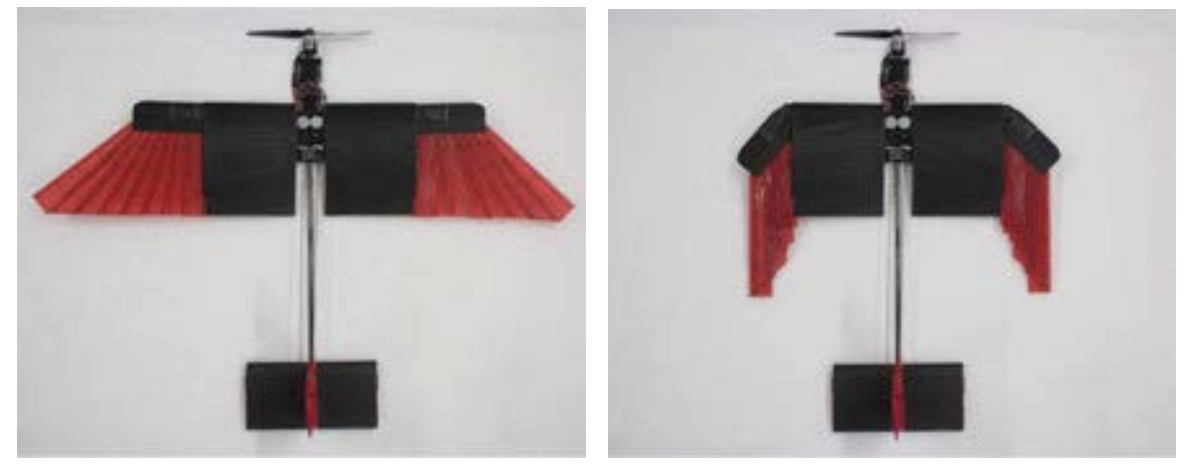

(b) Bioinspired feathered wing [63]

\section{Figure 8: Bioinspired folding wing}

\section{Modelling and Analysis of Morphing Wing}

Analysis and modelling play an important role in the TRL 1-3. In TRL 1, basic principles of morphing concepts are established; in TRL 2, the characteristics of morphing concepts are identified; and, in TRL 3, analytical studies are performed to set the morphing concepts into detailed design. Laboratory-based studies are conducted to validate the analytical predictions. Analysis and modelling also play an important role for validation of high fidelity approaches of morphing concepts for a variety of experimental and actual flight environment. The structural, aerodynamic, aeroelastic, control and optimisation methods for modelling and analysis are summarized below. Table 3 includes the analytical and computational methods that were applied to morphing wings with working prototypes. 


\subsection{Structure}

At the component level of the structure analysis, there are generally two methods: analytical homogenization method and finite element method (FEM). Ermakova et al [64] presented the shape optimisation of the corrugation for better performance of the morphing skin based on 2D thin beam elements. Considering that the ratio of Young's modulus of elastomer coating to that of the composite corrugated core is very small, the elastomer coating was neglected in the contact areas. The FEM analysis implemented in Abaqus 6.12 using S4R elements was used to evaluate the accuracy of the analytical homogenization methods [65] for the buckling modes of the corrugated panel. As the actuation forces are required to be very low, they make little contribution to the overall buckling. Therefore, the coupling between actuation and critical load is not investigated.

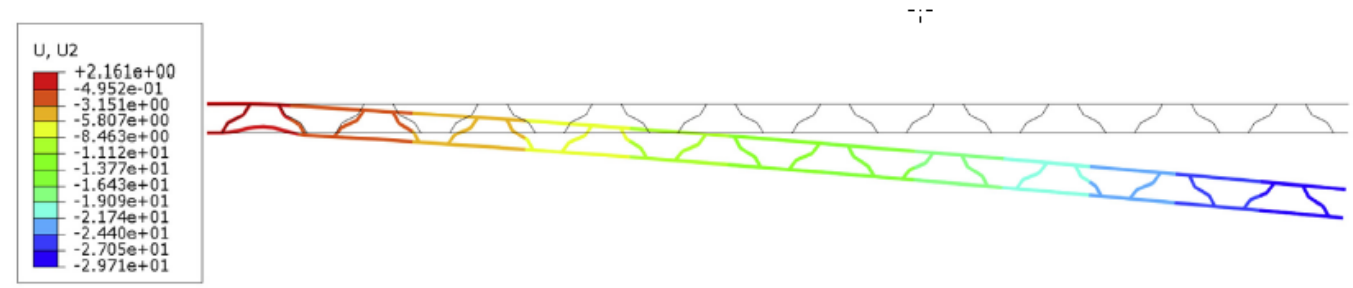

(a) Bending of the coated corrugated skin based on the thin beam elements [64]

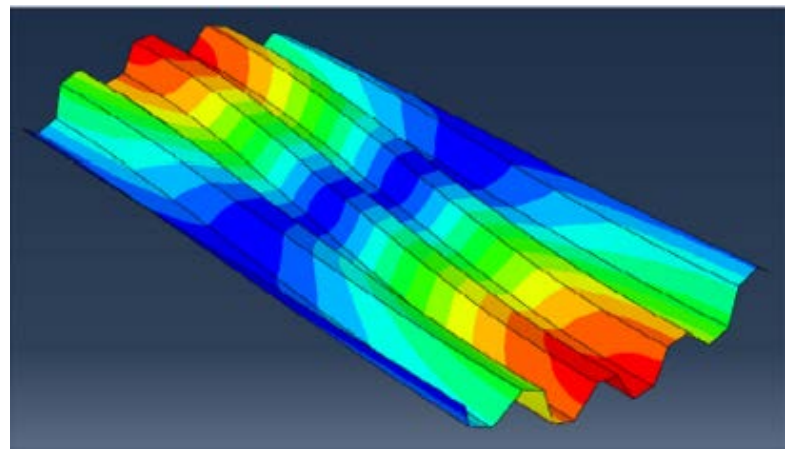

(b) Out-of-plane global buckling based on the S4R elements [65]

\section{Figure 9: Analyses with FEM}

If homogenization models retain their dependence on the physical geometry of the structure, they can be more easily integrated into the system level analysis than FEM. Based on Castigliano’s second theorem, Dayyani et al [160] presented two analytical solutions to calculate the equivalent tensile and bending flexural properties of the coated corrugated skins. Because elastomer coating and composite corrugated core are well adhered together and have the same displacement, the strain energy terms of the elastomer in contact with the glass fibre are neglected.

Dayyani et al [161] derived a generic super element for a unit cell of a corrugated core panel with an elastomeric coating, motivated by morphing aircraft structures. The direct stiffness method and Castigliano’s second theorem, together with appropriate boundary conditions, are applied to obtain 
the stiffness matrix of the generic super element which captures the small deformation of 2D thin curved beams with variable curvatures. The strain energy terms of the elastomer in contact with the composite material are also neglected.

For beams undergoing large deflections, geometric nonlinearity plays a significant role. Geometrically nonlinear effects may be included by introducing von Kármán strains [68]. An assumption is made that there is no variation in displacements, strains and stresses in the beam width direction. Combined with the Ritz method, the minimum total potential energy principle is applied to obtain an approximate solution of the present formulation.

For plates such as folding wings [93], it will be assumed that the Kirchhoff plate theory applies, and that plate rotations are negligible compared with unity (von Kármán assumption). The principle of virtual work is applied in establishing the structural equations of motion.

At the system level, the structure analysis is combined with other system level analyses such as aerodynamic analysis and control analysis. The structure equation of motion can be obtained by Newton's principles [66]. Stability was determined using a Strutt diagram based on the Mathieu's equation. Due to the periodicity of the flapping motion of the test ornithopter during free flight, the stiffness of the torsional spring representing the compliant spine was assumed to be linear, time periodic.

Lagrange's equations [67] can be also used to derive the system equations. A state of plane stress was assumed for the considered structures. An analytical model using the Ritz method is developed yielding important model properties for bi-stable wing-shaped composites.

The structural nonlinearity may also be considered at the system level, such as the piecewise linear stiffness and cubic stiffness. For a piecewise linear spring, the stiffness $K_{\theta}$ was varied based on the loads experienced by the aircraft [98]

$$
K_{\theta}=\left\{\begin{array}{cl}
1 . E^{12} & \text { if } K_{\theta} \theta \leq M_{\max } \text { and } t<t_{\text {release }} \\
1 . E^{0} & \text { if } K_{\theta} \theta>M_{\max } \text { and } t \geq t_{\text {release }}
\end{array}\right.
$$

where $M_{\max }$ is the predefined threshold value of hinge moment. The commercial multibody code LMS Virtual.Lab Motion was used for the nonlinear dynamic simulations of flexible multibody systems.

The nonlinear stiffness for an angular motion, $K_{\theta 1}$, is given as [87]

$$
K_{\theta 1}=k_{\theta 1} \times\left(1+\eta \theta_{1}^{2}\right)
$$

where $\theta_{1}$ is the elastic rotational angle. The dynamic equation of the folding wing is formulated by the Lagrange equations.

To build the nonlinear equation of the structure with free-play nonlinearity, the generalized mass matrix, $M_{s}$, stiffness matrix, $K_{s}$, and damping matrix, $B_{s}$, of the model are given as [85] 


$$
\begin{aligned}
& M_{s}=\left\{\begin{aligned}
M_{0} \quad \beta & >f p \\
M_{f}-f p & \leq \beta \leq f p \\
M_{0} \quad \beta & <-f p
\end{aligned}\right. \\
& K_{s}=\left\{\begin{array}{c}
K_{0} \quad \beta>f p \\
K_{f}-f p \leq \beta \leq f p \\
K_{0} \quad \beta<-f p
\end{array}\right. \\
& B_{s}=\left\{\begin{array}{c}
B_{0} \quad \beta>f p \\
B_{f}-f p \leq \beta \leq f p \\
B_{0} \quad \beta<-f p
\end{array}\right.
\end{aligned}
$$

where $\beta$ is the trailing edge deflection displacement, $f p$ is the value of half free-play. $M_{0}$ is the original mass matrix of the wing, while $M_{f}$ is the mass matrix of the wing without curved beams. $K_{0}$ is the original stiffness matrix of the wing, while $K_{f}$ is the stiffness matrix of the wing without curved beams. $B_{0}$ is the original damping matrix of the wing, while $B_{f}$ is the damping matrix of the wing without curved beams.

\subsection{Aerodynamics}

\subsubsection{Steady Aerodynamics}

Aerodynamic methods applied to the morphing wing are summarized in Table 4. They are often used as a preliminary design tool, due to high computational efficiency. Several different tools for aerodynamic performance prediction exist: a) linear methods; and b) computational fluid dynamics (CFD) methods.

Linear methods are based on potential flow theory and are best suited for thin lifting surfaces at small angles of attack (such as cruise flight). The panel potential flow method is widely used to simulate the steady aerodynamic behaviour in the design and optimization of morphing wings. They are based on the replacement of the wing boundaries by singularity panels, such as source panels, doublet panels and vortex panels. XFOIL is a computational solver for 2D aerofoils combining an inviscid panel method with a boundary layer formulation to predict lift, drag, and pitching moment for aerofoils in viscous flows [69]. Cody et al [70] used XFOIL to perform fast and relatively accurate 2D steady-flow simulations of different morphed configurations using a camber-controlled morphed wing for manoeuvring. Benjamin et al [71] compared a linear method, XFOIL, against the open source CFD solver OpenFOAM. XFOIL was found to provide very similar aerodynamic performance predictions to OpenFOAM, but at a fraction of the computational cost incurred by the CFD solver. Fincham et al [72] adopted XFOIL as the source of aerodynamic predictions. It was found that the performance of the morphing aerofoil was nearly as good as a hypothetical aerofoil whose shape can change arbitrarily (assuming an ideal morphing mechanism can be designed).

Extended lifting-line theory, which decomposes a 3D wing into a series of 2D aerofoils, is a 
common method of choice. Wickenheiser et al [162] presented an extension of Weissinger's method. It extends Prandtl's lifting-line theory to wings of arbitrary curvature and chord distribution and nonideal aerofoil cross sections. However, caution must be taken when considering flows with dominant viscous effects.

For the aerodynamic analysis of 3D morphing wings, vortex lattice method (VLM) is widely used. Tornado is a VLM code that neglects wing thickness and viscous effects. These limitations imply that Tornado can only be used for small angles of attack around slender wings. Ajaj et al [47] used Tornado for the aerodynamic predictions of span morphing wing. Li et al [105] used Tornado to calculate the lift coefficients and pitching moment coefficients of a lightweight flexible morphing wing by operating seamless leading-edge and trailing-edge control surfaces.

There are two kinds of methods for static aeroelastic analysis: structural analysis method and aerodynamic analysis method. The total time of the structural analysis is generally much shorter than that of the aerodynamic analysis. The choice of the methods is therefore dictated by the time needed to run the aerodynamic analysis. To perform static aeroelastic analyses for the optimisation of a morphing wing, linear aerodynamic methods are preferred for cost-related reasons. Bilgen et al [92] presented the static aeroelastic modelling and optimisation of a variable-camber aerofoil that employed two cascading bi-morph actuators in the top and bottom surfaces of the aerofoil, which are pinned at the trailing-edge. The coupling system of this semi-solid-state variable-camber aerofoil was constructed using XFOIL and ANSYS.

The optimisation problem of a 3D morphing wing is dealt with 3D panel methods or extended lifting line theory. Molinari et al [94] optimised another MFC actuated tailless morphing aircraft based on the 3D panel method. An improvement of 54\% for the rolling moment, 43\% for the pitchup moment at $30 \mathrm{~m} / \mathrm{s}$, and $378 \%$ for the pitch-down moment at $15 \mathrm{~m} / \mathrm{s}$ was obtained.

The deployment of CFD methods finds an adequate application in cases at large angles of attack and when the flow exhibits strong viscous effects. Woods et al [71] compared the OpenFOAM solver with XFOIL. The agreement between the two methods was found good for angles of attack up to roughly 8 deg, for all the geometries studied. Increasing differences were observed for increasing angles of attack, particularly for drag predictions.

One of the many challenges in a CFD analysis is the prediction of the laminar-to-turbulent transition, which may be relevant for the flow conditions at which some morphing wings are designed for. Gabor et al [74] compared CFD results with experimental wind tunnel testing for a morphing wing testbed. A mesh was generated to provide sufficiently accurate results. Numerical results were found in good agreement with experimental results for the pressure distribution, but failed to accurately capture the drag reduction observed in the experiments.

Despite several computational difficulties, CFD is generally preferred over linear methods to 
increase the accuracy of predictions when a limited number of analyses are needed. Spadoni et al [163] investigated various design configurations of chiral-core aerofoils based on the static aeroelastic analysis. The entire flow field is resolved using the Euler equations. Ismail et al [95] investigated a twist morphing MAV wing and compared its aerodynamic characteristics with a rigid wing. The aerodynamic performance was calculated solving the 3D incompressible Reynoldsaveraged Navier-Stokes (RANS) Shear Stress Transport equations. Aerodynamic investigation on PR-compliant wing has shown its ability in generating a higher nonlinear lift distribution compared to PR or rigid wing type.

When CFD is employed in the optimisation of a morphing wing, a gradient-based optimizer is preferred to limit the number of CFD evaluations. Lyu et al [75] used a CFD solver SUmb to optimize the adaptive morphing trailing-edge wing. SUmb is a finite-volume, cell-centered multiblock flow solver that solves the RANS equations using a Spalart-Allmaras turbulence model. A sequential quadratic programming method (SNOPT) was used, which can solve large-scale nonlinear optimization problems with thousands of constraints and design variables.

\subsubsection{Unsteady Aerodynamics}

Compared to traditional aerodynamic theory, the flexibility of whole or part of the aerofoils should be considered. A state space aerodynamic theory for flexible aerofoils was proposed by Peters et al [76] which can be assembled with other dynamic codes and used for either time-marching, eigenvalues, or control system design. This theory has been applied to the aeroelastic analysis of flexible aerofoils [77]-[79]. To explore the combined aeroelastic behaviour and gust response of a flexible aerofoil, the aerodynamic loads were accounted for via Peters' state-space model for the case of a morphing aerofoil [79].

There are also some other aerodynamic theories considering the flexibility of aerofoils that were reviewed [80] [82]. A systematic application of extended unsteady thin aerofoil theory of von Kármán and Sears to a general deforming aerofoil was outlined by Johnson [80]. The theory developed by Theodorsen and Garrick, which is restricted to rigid body motion, was extended for the unsteady aerodynamics of deformable thin aerofoils. This method used conformal mapping to develop the flow around the flat plate based on the flow around a circle in two dimensions [81].

Unsteady aerofoil theory combined with strip theory can be used to model the aerodynamic forces of 3D morphing wing in the frequency domain. Wang et al [100] presented a general aeroelastic model that predicts the flutter speed and flutter frequency of a folding wing with simplified geometry but with an arbitrary number of wing segments. The unsteady aerodynamic forces are modelled using strip theory and generalized Theodorsen unsteady aerofoil theory. The beam-theory structural model and unsteady aerodynamic model are coupled using Lagrange’s 
equations. Three configurations were manufactured to study the behaviour of two-segment, threesegment, and four-segment folding wings. It was found that the agreement between the theory and experiment degraded as the wing was divided into more segments.

Unsteady vortex lattice method (UVLM) is often used to simulate the morphing process in the time domain. It is assumed that the flow field is inviscid, incompressible and irrotational. For morphing wing cases, the matrix of influence coefficients changes and must be reformed and solved at every time step. Thus, UVLM is readily adaptable to different wing geometries and morphing processes [83]. Ghommem et al [84] consider active shape morphing to optimize the flight performance of flapping wings based on the UVLM. The results show that the spline-based morphing, which requires specification of more design variables, yields a significant improvement in terms of propulsive efficiency. Ren et al [96][97] developed a first-order state-space aeroelastic model combining reduced-order UVLM and Euler-Bernoulli beam theory with time-dependent boundary conditions. Results showed that critical flutter speed of the variable-span wing was very sensitive to the span length since it had remarkable effects on structural stiffness properties and aerodynamic characteristics.

The Doublet lattice method (DLM) is employed to model the aerodynamic forces in the frequency domain. The DLM is often used as the first step in the aeroelastic analysis [85][86][87]. A flexible wing-folding device for loads alleviation was investigated by Castrichini et al [98]. The commercial multibody code LMS Virtual.Lab Motion was used to construct the structural model. The aerodynamic influence coefficients matrix was evaluated by means of DLM. The effect of the passive non-linear hinge was studied in the condition of "one-minus-cosine” gusts. Shrestha et al [99] investigated the effect of changes in folding angles on the flutter speed and frequency. The structural and aerodynamic models were created using MSC.PATRAN FlightLoads. The enhancement of the flutter characteristics of an aluminium folding wing was proposed by varying the outboard wing folding angle independently of the inboard wing folding angle. It was clearly found that the flutter characteristics were strongly influenced by changes in the inboard/outboard folding angles, and a significant improvement in the flutter characteristics of a folding wing could be achieved by varying its outboard wing folding angle. Pecora et al [101] worked on the definition of aeroelastically stable configurations for a morphing wing trailing-edge driven by conventional electromechanical actuators. Matrices of unsteady aerodynamic influence coefficients were evaluated by means of DLM. The structural model was established based on the FEM. Obtained results showed that for the most practical combinations of trailing-edge stiffness and inertial distributions, flutter is avoided if sufficient stiffness is provided by the actuation chain.

Approximation methods transfer the aerodynamic forces from frequency domain to transfer functions of the Laplace variable to be used in aero-servo-elastic applications. An investigation was 
made into the nonlinear aeroelastic behaviour of a composite wing with morphing trailing-edge actuated by curved beams by Li et al [85]. Roger's approximation and DLM can be used to calculate the unsteady aerodynamic influence coefficients matrix. The structural model was established based on the FEM validated by the impact test of the experimental model involving the effect of free-play nonlinearity between discs attached to the curved beams and wing skins. Numerical simulations show that the aeroelastic responses of the nonlinear system converge slower than the linear one at low flow velocity and diverge faster when the velocity is higher than the critical flutter speed.

CFD method can be used for the simulation of the unsteady aerodynamics during the morphing stage especially for rapid changes in the aerodynamics raise. A dynamic grid technology was used to simulate the unsteady flow-field boundary movement and the mesh around an UAV [88] . The grid updating stage was changed automatically according to each iteration step based on the spring-based smoothing, and local remeshing method. Lift and drag coefficients for the canard and wing vary significantly. Significant increase in the hinge moment is also observed during the first morphing stage but the sign of the moment remains the same throughout.

Reduced order methods (ROM) based on CFD method are rather popular methods in dynamic aeroelasticity. Liu et al [90] conducted a continuous dynamic simulation for morphing wing aeroelasticity based on a ROM. It was found that limit-cycle oscillation (LCO) amplitudes predicted by the ROM approach agreed well with the direct CFD approach, but phase shifting occurs as the LCO develops.

\subsection{Control of Morphing Wing}

\subsubsection{Transformation Between Different States}

Because morphing aircraft have more than one state, the stability and control of the transformation process between different states is crucial. For aerofoil morphing, the major control objective is to reach the desired shapes, which is also one type of state transformation. Dimin et al [102] presented an approach to control the shape of a morphing wing by employing internal, integrated actuators acting on the morphing trailing-edge. The control action aims at producing small adaptive trailing edge shape changes for optimal aerodynamic performance by varying the trailing edge camber in a way corresponding to a rigid trailing edge deflection in the range -5 to +5 deg during flight. Both feed-forward and feedback control logic architectures were detailed and numerically investigated.

The state transformation is the control objectives of variable-sweep morphing aircraft and folding-wing morphing aircraft. Shi et al [103] presented the dynamic principle of internal structure 
of a sweep morphing wing, with the purpose of changing the sweepback angle rapidly and smoothly. The controller is divided into three subsystems, which are designed independently: the control allocator is designed based on pseudo inverse method as shown in Figure 10; the linearization and the decoupling of the original system were achieved by the dynamic inversion controller; two PID controllers are designed based on classical linear control theory.

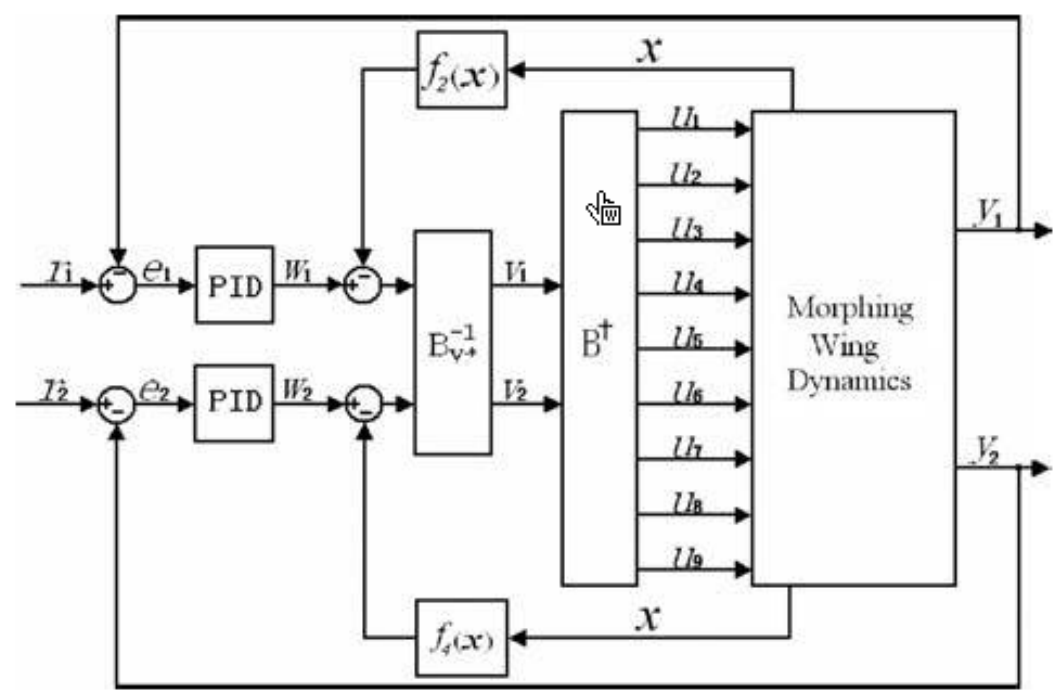

Figure 10: Block diagram of the control system of the sweep morphing wing [103]

\subsubsection{State Transformation of Flight Dynamics}

Because the morphing control has the potential to replace the traditional control effectors, the stability and control of flight dynamics of morphing wing aircraft has been investigated. For the area of aerofoil level morphing, Li et al [105] developed an active controller of both leading and trailingedge control surfaces to enhance longitudinal stability. Based on the pole placement, a controller was designed for active control of the leading and trailing-edge control surfaces, transforming the longitudinal performance of instability to the requirements of level 1 flying quality. Wang et al [106] studied the morphing aircraft rolling control based on the morphing camber based on operating several pairs of flexible leading and trailing-edge seamless surfaces. An iteration method of pseudoinverse allocation and quadratic programming allocation within the constraints of actuators was investigated to solve the nonlinear control allocation caused by the aerodynamics of the control effectors. The simulation results showed that the control method based on control allocation could achieve the control target.

For the area of variable-sweep morphing aircraft, Tong et al [107] presented an aircraft roll control strategy through the asymmetric changes of wing sweep angle. Multi-body dynamic model is built based on Kane's method. An integrated design of trajectory tracking control is presented via 
constrained back-stepping method. Stability of the presented control law was discussed in the sense of Lyapunov. Liu et al [108] developed a robust control methodology for one type of morphing aircraft where distributed arrays of hundreds of shape change devices are employed to stabilise and manoeuvre the air vehicle. He et al [109] presented a tensor product modelling method and a tensor product (TP) model-based control design method for a type of morphing aircraft in transition process. Results show that the designed controller was effective in the whole allowable flight range of variable-sweep morphing aircraft. Zhang et al [110] simplified the physical model of a variablespan and variable-sweep morphing aircraft to build a six degree-of-freedom dynamic model, so that the longitudinal dynamic model could be linearized for loiter and dash configurations, and the controllers were designed for these two shapes with pole-placement. Wang et al [104] presented an attitude control of variable sweep morphing aircraft based on switched systems approach. The finitetime robust control was introduced to guarantee the flight stability instead of the traditional asymptotic stability. Simulation results showed that the proposed approach was effective for the morphing flight and achieved a proper trade-off between the control performance and elevator deflections.

In the domain of folding wings, Colorado et al [111] proposed an attitude controller named backstepping with desired angular acceleration function as shown in Figure 11. Simulations and windtunnel experimental results showed an increase of about $23 \%$ in net body force production during the wingbeat cycle. Yue et al [112] investigated gain self-scheduled H1 robust control system design for a tailless folding-wing morphing aircraft in the wing shape varying process. Longitudinal nonlinear dynamic equations of the morphing aircraft in wing shape varying are simplified and transformed to a linear parameter varying model. Results showed that gain self-scheduled H1 robust controller can guarantee relative small changes of speed and altitude during the wing folding process.

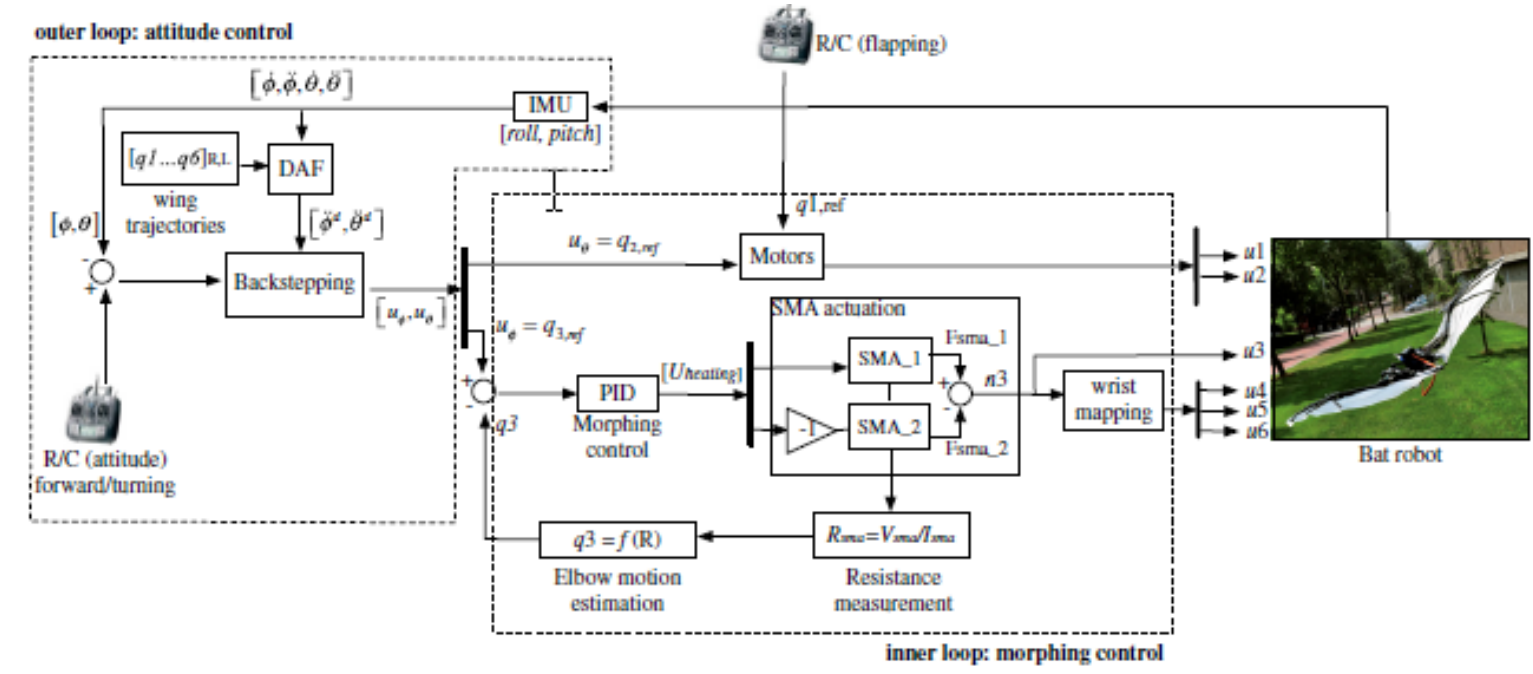

Figure 11: Flight control architecture scheme for bat robot [111]

Pecora et al [113] proposed a numerical investigation that analyses the roll control strategies 
based on twist morphing wing. Results show that the asymptotic roll rates produced by wing twist morphing were approximately 1.6 times greater than the rates produced by ailerons.

\subsection{Optimisation Design}

The design of morphing wing is always a trade-off between different objective functions. As an example, the objective functions may be: structural weight, energy needed to sustain and change the state of the wing, aerodynamic characteristics (drag, lift at one or more flight conditions), control effort, etc. The design variables can be classified into two types: the shape variables (such as the control points of aerofoil) and the structural variables (such as the location and dimension of actuators). The optimisation methods can be classified into three types: topology optimisation algorithms [114][115] [116], parameter optimisation (gradient-based optimisation algorithms [117] [119]), and evolutionary optimisation (algorithms [120]-[132]).

Topology optimisation can be used in the design of morphing areas such as the morphing leading or trailing-edge. Tong et al [115] proposed an approach for designing the compliant adaptive wing leading-edge with composite material based on the topology optimisation. The models of topology optimisation of compliant adaptive wing leading-edge with glass fibre reinforced epoxy composite were built using solid isotropic material with penalization (SIMP) method. An objective function was used to minimise the LSE between deformed and desired shape. The compliant wing leading-edges with different fibre ply-orientations were generated by the optimality criteria (OC) method and sensitivity filtering technique. Multi-objective population-based incremental learning method was used to optimise the percentage of change in lift effectiveness, buckling factor, and mass of a structure subject to design constraints including divergence and flutter speeds, buckling factors, and stresses [116].

Gradient-based optimisation algorithm is often used in conjunction with an adjoint method that computes the required derivatives in the aerodynamic design optimisation. Zhoujie et al [117] quantified the aerodynamic performance benefits of a morphing trailing edge using aerodynamic design optimisation. Stanford et al [118] considered the design optimisation of a flapping wing in forward flight with active shape morphing, aimed at maximising propulsive efficiency under lift and thrust constraints. Nitin et al [119] proposed an efficient, high-fidelity hydrodynamic shape optimisation tool for 3D lifting surfaces operating in viscous and nearly incompressible fluids, with consideration for cavitation and over a range of operating conditions.

Evolutionary optimisation algorithms are mostly used in the design of morphing wings. Molinari et al [121] presented an approach to optimise concurrently the variables describing the wing external shape, the internal compliant structure, and the embedded actuators. The wing is actuated by means of smart materials embedded into the structure. The internal compliant structure, which guides the 
aerofoil deformation, is described by a Voronoi graph-based parameterisation. The resulting morphing wing concept can therefore attain optimal contour shapes both when inactive and when actuated, thus possessing the potential for achieving the required aerodynamic performance. Srinivas et al [122] provided an overview of the design and experimental work of compliant wing and wingtip morphing devices conducted within the NOVEMOR project and was shown that the optimisation tools developed can be used to synthesize compliant morphing devices. Kai et al [123] proposed a procedure to synthesize planar rigid-body mechanisms, containing both prismatic and revolute joints, capable of approximating a shape change defined by a set of morphing curves in different positions. Koreanschi et al [124] optimised the drag coefficient and the laminar-to-turbulent transition for the aerofoil component of a wing model using an adaptive upper surface with two actuation points. The effects of the new shaped aerofoils on the global drag coefficient of the wing model were also studied. Gaspari et al [125] presented an optimisation procedure for the shape design of morphing aircraft. The process was coupled with a knowledge-based framework combining parametric geometry representation, multidisciplinary modelling, and genetic algorithm. The parameterisation method exploits the implicit properties of the Bernstein polynomial least squares fitting to allow both local and global shape control. Howoong et al [126] developed a model for aerodynamic work with a simple linear-spring energy model to acquire a more complete energy model for a morphing aerofoil than previous studies. The updated morphing energy model was applied to a subsonic design problem based on a high-altitude, long-endurance aircraft, and multi-objective solutions that attempt to minimise actuation energy and minimise drag were sought. Sleesongsom et al [127] developed an improved version of an opposite-based multiobjective population-based incremental learning approach and the use of a multigrid ground element strategy to synthesize a wing structure. Botez et al [128] presented the numerical analysis, manufacturing and subsequent testing of two rigid wing models based on the original aerofoil of the ATR 42 aircraft and a morphed aerofoil optimized from the original for the specific case of Mach number of 0.1 and angle of attack of 1 deg. Wu et al [129] provided a method for designing and optimizing the bi-stable deployable structure of morphing skin considering the air flow. The immune genetic algorithm (IGA) program performs well during optimisation and offers the optimal solution in the example because of the function of vaccination and immune selection in IGA. Olympio et al [130] presented a multi-objective topology optimisation approach to a one-dimensional morphing aircraft structure problem. The multi-objective approach helped to illustrate the compromise between the selected requirements for a morphing skin, specifically the low in-plane stiffness and the low transverse displacement under out-of-plane pressure loading. Several topologies of cellular structures were found based on the minimum. Figure 12 shows the triangular scatter plot matrix showing solutions located near the Pareto front. Smita et al [131] presented a methodology for the optimal design of morphing aircraft wings. The problem 
formulation considered a multi-objective, multi constraint, and discrete continuous set of design variables. A very computationally intensive problem was considered and solved using NSGA II. Nonlinear FEM analysis was used to address the large deformation requirements of the problem. Kai et al [132] used genetic algorithm and rigid-body mechanism topologies to synthesise distributed compliant mechanisms that approximate a shape change defined by a set of morphing curves in different positions.
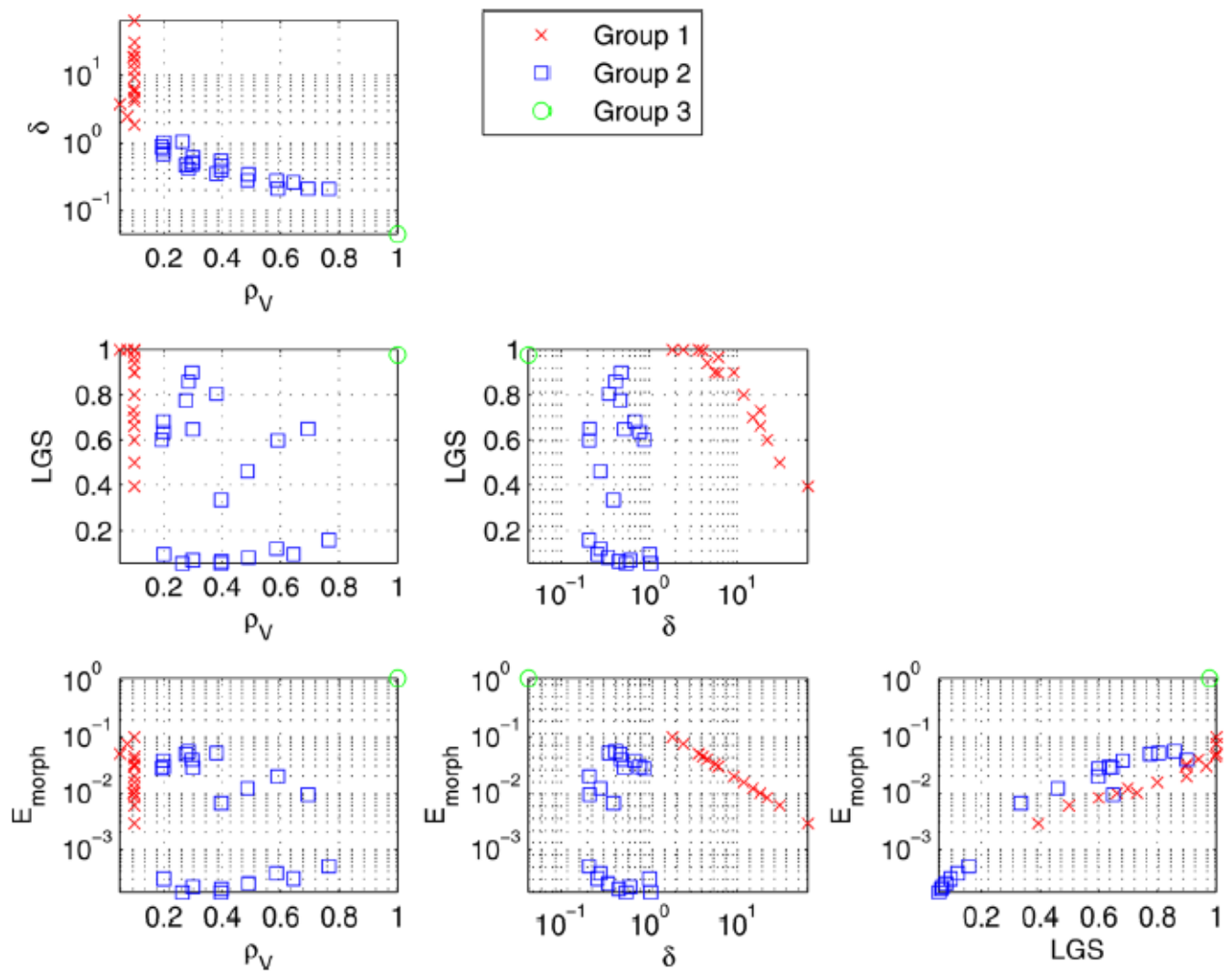

Figure 12: Triangular scatter plot matrix showing solutions located near the Pareto front [130]

\section{Conclusions}

Morphing a wing in flight may improve the aircraft overall performance or specific target parameters. This is achieved by shaping appropriately the wing to different and critical phases of flight. There is a large body of work proposing novel concepts of morphing wings, as shown in this review, and some of these concepts have seen a practical experimentation on either a two or threedimensional wing test model, although the latter examples are rarer. Unmanned aerial vehicles provide access to a low-cost, expendable experimental platform, suitable for testing unconventional technologies. This is the main reason that most of the experiments carried out on morphing technologies are demonstrated on unmanned aerial vehicles. To date, it is apparent that the deployment of morphing technologies on aerial vehicles, for uses other than proof-of-concept demonstrations, is scarce and not entirely successful. The reasons for this may be attributed to two 
factors. The first factor is that research should be conducted at the material level, developing and understanding new advanced materials, and at the global level, developing new morphing concepts. These fields are generally studied by researchers of very different background, and the challenge here lies in the integration of different knowledge fields. A leap change in morphing technologies may originate from coordinated progress made in both fields. The second reason may reflect the predominant approach to develop morphing concepts, namely the “test-and-fix” approach. Relying often on new technologies and less common materials, experimentation plays an important part in expanding the knowledge behind most of the morphing concepts. This is not unexpected because, on the contrary of those standard technologies embedded on transport aircraft, there is a limited knowledge at the disposal of aircraft designers. In this scenario, there is a similar lack of confidence in the methods and tools needed to analyse the multi-scale functional behaviour of a morphing concept and the mechanisms. Rather, it is apparent that the methods and tools used for conventional aircraft are re-used for the analysis and design of morphing concepts.

It is worth stressing that past and present morphing concepts tend to emulate the natural world. Aerofoil-level morphing designs produce changes to the aerofoil curvature, in a manner similar to the changes in feathers curvature driven by dedicated tendons. Wing-level morphing designs are inspired by the ability of birds to glide, perch, hunt, and escape. Today, designers and engineers can make use of the systematic and organised material collected in the website https://asknature.org/. As presented in this review, a large body of work proposed a variety of morphing devices. There is, however, a feeling that actuation and sensing are lagging behind the state-of-the-art in morphing. In fact, a morphing system needs to be considered as a whole system, or a system of systems: 1) relevant information needs to be sensed, from either the surrounding environment (fluid properties, etc.) or the system (deformations, attitudes, etc.), or both; 2) the sensed information needs to be postprocessed to produce a decision based on a control system; 3) the control system needs to activate the actuators, which needs to be fast enough to achieve the commanded control targets.

Some further considerations follow below.

\subsection{Morphing Concepts Integration}

Although morphing wings have advantages over traditional wings in terms of performances, they are equally limited by weight constraints and actuation concepts. Two-dimensional morphing is not as efficient in performance as 3D morphing [159]; however, 3D morphing concepts also bring extra weight and complications. The higher the morphing level, the larger the weight introduced by the morphing concept, and the higher the achievable performance will be compared to conventional 
wings. When assessed considering additional fuel needed on-board, morphing concepts lose their attractiveness, holding back their integration on series production.

Combinations of morphing concepts are trade-off between weight and performances which may produce better configurations. Promising combinations of concepts are: 1) the integration of span-wise morphing and variable sweep morphing [133]; and 2) the combination of span-wise morphing and variable camber morphing [42]. Furthermore, span-wise morphing trailing-edge [134] is a morphing design that combines the concept of bending morphing both in the span-wise and chord-wise directions, which could potentially lead to better aerodynamic performance than traditional morphing trailingedge devices.

\subsection{Structure and Actuation Materials}

Although various smart materials have been applied to actuate the morphing wing, their disadvantages often restrict their practical use. Piezoelectric materials offer relatively high force output in a wide frequency bandwidth; however, the strain output is relatively low. Although the achievable aerodynamic changes of SMA actuation are suitable for in-flight mission adaptation of the wing, the slow cooling rate of the SMA actuation is not appropriate for the flight control applications. Cellular materials [53] are more suitable for morphing wings compared to traditional materials.

\subsection{Modelling and Analysis Methods}

Analysis and modelling play a key role in the TRL 1-3 in identifying the characteristics of morphing concepts and defining the morphing concepts. Furthermore, they play an important role in assisting the realisation of morphing concepts before a variety of experimental and actual flight tests are conducted. The structural and aerodynamic analysis and modelling methods are very important in the design stage of the morphing wing. Wind tunnel and flight tests are the verification of the design methods. Often, analysis models are updated according to wind tunnel and flight test data. Once the models are updated, they are deployed to optimize the morphing wing performances and to implement appropriate control strategies.

Structural models for morphing concepts including variable camber, variable thickness, twist morphing and span morphing are generally based on FEM for generality of applications. For morphing concepts based on variable sweep and for folding wings, methods include FEM and multibody dynamics to analyse complex mechanisms.

Unsteady vortex lattice method has potential for being used in morphing concepts based on variable camber, variable thickness, twist morphing and span morphing. Doublet-lattice method is preferred in the analysis of variable sweep morphing concepts and folding wings. Despite a number of existing attempts, the use of reduced order models based on CFD is expected to grow in all areas of 
morphing, as they may offer in the near future a good compromise between robustness of the solution process and efficiency/accuracy of the solution.

Topology optimisation finds a clear application to design morphing leading or trailing-edge devices. Further insights into the optimal structural design of 2D morphing concepts may be obtained using multiscale, concurrent design methods. Gradient-based optimisation methods are adequate to analyse cases where the morphing concepts exhibit small changes from the baseline configuration, such as twist morphing, span morphing and variable sweep, but their application may be extended to analyse folding wings as well.

Although many modelling and analysis methods for morphing concepts have been proposed, only a few have been tested. More fight tests should be conducted for morphing wing aircrafts to verify the modelling and analysis methods.

\section{Acknowledgements}

The authors gratefully acknowledge the support from the Natural Science Foundation of China under grant numbers 11402014 and 11572023. Dr Da Ronch and Dr Drofelnik gratefully acknowledge the financial support from the Engineering and Physical Sciences Research Council (grant number: EP/P006795/1). 
Table 1: Timeline of morphing-wing concepts

\begin{tabular}{|c|c|c|c|c|c|}
\hline Year & Information & Concept & $\begin{array}{l}\text { Wind } \\
\text { tunnel }\end{array}$ & Flight & Reference \\
\hline 1903 & Wright Brothers' flyer & twist morphing & & $\checkmark$ & {$[136]$} \\
\hline 1920 & $\begin{array}{l}\text { Parker variable-camber } \\
\text { wing }\end{array}$ & $\begin{array}{l}\text { variable } \\
\text { camber }\end{array}$ & $\checkmark$ & & [137] \\
\hline $\begin{array}{c}1979- \\
1989\end{array}$ & AFTI/F-111 MAW & $\begin{array}{l}\text { variable sweep } \\
\text { \& camber }\end{array}$ & $\checkmark$ & $\checkmark$ & [138] \\
\hline $\begin{array}{c}1995- \\
1999\end{array}$ & $\begin{array}{l}\text { Smart Wing Program } \\
\text { Phase I concepts }\end{array}$ & $\begin{array}{l}\text { variable } \\
\text { camber }\end{array}$ & $\checkmark$ & & [139] \\
\hline $\begin{array}{l}1996- \\
2001\end{array}$ & Active aeroelastic wing & $\begin{array}{l}\text { variable } \\
\text { camber }\end{array}$ & $\checkmark$ & $\checkmark$ & [140] \\
\hline $\begin{array}{c}1997- \\
2001\end{array}$ & $\begin{array}{l}\text { Smart Wing Program } \\
\text { Phase I concepts }\end{array}$ & $\begin{array}{l}\text { variable } \\
\text { camber }\end{array}$ & $\checkmark$ & & [141] \\
\hline 1999 & Active hydrofoil & $\begin{array}{l}\text { variable } \\
\text { camber }\end{array}$ & $\checkmark$ & & [142] \\
\hline 1999 & Finger concept by DLR & $\begin{array}{l}\text { variable } \\
\text { camber }\end{array}$ & & & [143] \\
\hline 2000 & Belt-rib concept by DLR & $\begin{array}{l}\text { variable } \\
\text { camber }\end{array}$ & & $\checkmark$ & [31] \\
\hline 2000 & $\begin{array}{l}\text { FlexSys mission-adaptive } \\
\text { compliant wing }\end{array}$ & $\begin{array}{l}\text { variable } \\
\text { camber }\end{array}$ & $\checkmark$ & $\checkmark$ & [144] \\
\hline $\begin{array}{l}2003- \\
2006\end{array}$ & $\begin{array}{l}\text { Lockheed Martin Z-wing } \\
\text { concept }\end{array}$ & folding wing & $\checkmark$ & & [145] \\
\hline $\begin{array}{c}2003- \\
2006\end{array}$ & $\begin{array}{l}\text { NextGen aeronautics bat- } \\
\text { wing concept }\end{array}$ & variable sweep & $\checkmark$ & & [146] \\
\hline 2003 & $\begin{array}{l}\text { SMA reconfigurable } \\
\text { aerofoil }\end{array}$ & $\begin{array}{l}\text { variable } \\
\text { camber }\end{array}$ & $\checkmark$ & & [147] \\
\hline 2003 & HECS wing & span morphing & & & [148] \\
\hline 2004 & $\begin{array}{l}\text { Multi-section variable- } \\
\text { camber wing }\end{array}$ & $\begin{array}{l}\text { variable } \\
\text { camber }\end{array}$ & $\checkmark$ & & [149] \\
\hline 2004 & $\begin{array}{l}\text { Variable-gull-wing } \\
\text { morphing aircraft }\end{array}$ & folding wing & & $\checkmark$ & [150] \\
\hline 2004 & $\begin{array}{l}\text { Virginia Polytechnic } \\
\text { Institute and State } \\
\text { University telescoping- } \\
\text { wing aircraft }\end{array}$ & span morphing & $\checkmark$ & $\checkmark$ & [151] \\
\hline 2005 & Morphing inflatable wing & $\begin{array}{c}\text { variable } \\
\text { camber \& twist } \\
\text { morphing }\end{array}$ & $\checkmark$ & $\checkmark$ & [152] \\
\hline
\end{tabular}




\begin{tabular}{|c|c|c|c|c|c|}
\hline 2006 & Morphing HECS wing & $\begin{array}{c}\text { variable sweep } \\
\text { \& twist } \\
\text { morphing }\end{array}$ & $\checkmark$ & & {$[153]$} \\
\hline 2007 & $\begin{array}{l}\text { Pneumatic telescoping } \\
\text { wing }\end{array}$ & span morphing & $\checkmark$ & & {$[154]$} \\
\hline 2007 & Supekar morphing wing & span morphing & $\checkmark$ & & [155] \\
\hline 2008 & $\begin{array}{l}\text { Antagonistic SMA-based } \\
\text { morphing aerofoil }\end{array}$ & $\begin{array}{l}\text { variable } \\
\text { camber }\end{array}$ & & & {$[2]$} \\
\hline 2008 & $\begin{array}{l}\text { Bistable composite } \\
\text { morphing-wing concepts }\end{array}$ & variable sweep & & & {$[156]$} \\
\hline 2008 & $\begin{array}{l}\text { Morphlet (morphing } \\
\text { winglet) }\end{array}$ & folding wing & & & [157] \\
\hline 2009 & $\begin{array}{l}\text { Adaptive wing with SMA } \\
\text { torsion actuators }\end{array}$ & $\begin{array}{l}\text { variable } \\
\text { camber }\end{array}$ & & & [158] \\
\hline 2010 & $\begin{array}{l}\text { Warp-controlled twist } \\
\text { morphing wing }\end{array}$ & twist morphing & & & {$[56]$} \\
\hline 2011 & $\begin{array}{l}\text { Spa extending morphing } \\
\text { wing }\end{array}$ & span morphing & $\checkmark$ & & [43] \\
\hline 2012 & $\begin{array}{l}\text { Multisegmented Folding } \\
\text { Wing }\end{array}$ & folding wing & $\checkmark$ & & {$[100]$} \\
\hline 2012 & $\begin{array}{l}\text { SADE: seamless } \\
\text { aeroelastic wing }\end{array}$ & $\begin{array}{l}\text { variable } \\
\text { camber }\end{array}$ & & & [106] \\
\hline 2013 & $\begin{array}{l}\text { Adaptive bending-twist } \\
\text { coupling wing }\end{array}$ & twist morphing & & & [58] \\
\hline 2013 & Bat-like morphing-wing & folding wing & $\checkmark$ & & {$[111]$} \\
\hline 2014 & $\begin{array}{l}\text { Compliant adaptive wing } \\
\text { leading edge }\end{array}$ & $\begin{array}{l}\text { variable } \\
\text { camber }\end{array}$ & & & [115] \\
\hline 2015 & Span-extending blade tip & span morphing & & & {$[44]$} \\
\hline 2015 & $\begin{array}{l}\text { variable-span morphing } \\
\text { wing }\end{array}$ & span morphing & $\checkmark$ & & [45] \\
\hline 2015 & $\begin{array}{l}\text { Spanwise morphing } \\
\text { trailing edge }\end{array}$ & $\begin{array}{l}\text { variable } \\
\text { camber }\end{array}$ & $\checkmark$ & & [134] \\
\hline 2016 & GNATSpar wing & span morphing & $\checkmark$ & & {$[46]$} \\
\hline 2016 & $\begin{array}{l}\text { Twist morphing wing } \\
\text { segment }\end{array}$ & twist morphing & $\checkmark$ & & {$[57]$} \\
\hline 2016 & morphing wing-tip & $\begin{array}{l}\text { variable } \\
\text { camber }\end{array}$ & $\checkmark$ & & {$[74]$} \\
\hline 2016 & $\begin{array}{l}\text { Compliant structures- } \\
\text { based wing and wingtip } \\
\text { morphing devices }\end{array}$ & $\begin{array}{l}\text { variable } \\
\text { camber }\end{array}$ & $\checkmark$ & & [122] \\
\hline 2017 & Feathered wing & folding wing & & $\checkmark$ & [63] \\
\hline 2017 & Aquatic micro air vehicle & variable sweep & & $\checkmark$ & [49] \\
\hline
\end{tabular}


Table 2: Mapping between morphing strategies (design solutions) and objectives (design problem)

\begin{tabular}{|l|l|c|}
\hline \multicolumn{1}{|c|}{$\begin{array}{c}\text { Morphing } \\
\text { strategy }\end{array}$} & \multicolumn{1}{|c|}{ Purpose } & \multicolumn{1}{|c|}{$\begin{array}{c}\text { Morphing } \\
\text { level }\end{array}$} \\
\hline Variable Camber & $\begin{array}{l}\text { Performance } C_{L} / C_{D} \\
\text { Noise reduction } \\
\text { Flight control (roll, pitch, yaw) }\end{array}$ & Low \\
\hline $\begin{array}{l}\text { Variable } \\
\text { thickness }\end{array}$ & $\begin{array}{l}\text { Performance } C_{L} / C_{D} \\
\text { Low-speed performance improvement }\end{array}$ & Low \\
\hline Twist morphing & Flight control (roll, pitch) & Medium \\
\hline Span morphing & $\begin{array}{l}\text { Performance } C_{L} / C_{D} \\
\text { Flight control (roll) }\end{array}$ & High \\
\hline Variable sweep & $\begin{array}{l}\text { Performance } C_{L} / C_{D} \\
\text { Flight control (turn radius) } \\
\text { Disturbance rejection (crosswind) }\end{array}$ \\
\hline Folding wing & Performance $C_{L} / C_{D}$ & High \\
\hline
\end{tabular}


Table 3: Generic classification of methods deployed for the analysis of morphing wings but limited to those references with working prototypes

\begin{tabular}{|c|c|c|c|c|}
\hline Reference & Structure & Aerodynamic & Control & Optimization \\
\hline$[15]$ & $\begin{array}{l}\text { 3D FEM: shell } \\
\text { elements }\end{array}$ & XFoil & & \\
\hline [18] & $\begin{array}{l}\text { 3D FEM: shell } \\
\text { element s }\end{array}$ & & & $\begin{array}{l}\text { Fully stressed } \\
\text { design }\end{array}$ \\
\hline [20] & $\begin{array}{l}\text { 3D FEM: shell } \\
\text { elements }\end{array}$ & Steady CFD & & \\
\hline [27] & $\begin{array}{l}\text { 3D FEM: shell } \\
\text { elements }\end{array}$ & & & Simplex search \\
\hline [29] & & Steady CFD & & \\
\hline$[30]$ & $\begin{array}{l}\text { Analytical } \\
\text { (Bernoulli's theory) }\end{array}$ & & & \\
\hline [32] & $\begin{array}{l}\text { 3D FEM: shell } \\
\text { elements }\end{array}$ & DLM & & \\
\hline [33] & & & $\begin{array}{l}\text { Internal model } \\
\text { control }\end{array}$ & \\
\hline [34] & & & $\begin{array}{l}\text { PID \& an on/off } \\
\text { switch controlling } \\
\text { the SMA heating }\end{array}$ & \\
\hline [35] & & & Fuzzy PID & \\
\hline [37] & & & PID \& self-tuning & \\
\hline [40] & & XFoil & & $\begin{array}{l}\text { Hill climbing } \\
\text { method, } \\
\text { simulated } \\
\text { annealing search }\end{array}$ \\
\hline$[46]$ & $\begin{array}{l}\text { 3D FEM: rigid rib } \\
\text { elements }\end{array}$ & XFLR5 & & \\
\hline [55] & $\begin{array}{l}\text { 3D FEM: solid } \\
\text { elements }\end{array}$ & Steady CFD & & $\begin{array}{l}\text { Quadratic } \\
\text { Lagrangian } \\
\text { algorithm }\end{array}$ \\
\hline$[56]$ & & Steady VLM & & \\
\hline$[58]$ & $\begin{array}{l}\text { 3D FEM: shell and } \\
\text { solid elements }\end{array}$ & XFoil & & \\
\hline [67] & $\begin{array}{l}\text { Analytical } \\
\text { (Lagrange's } \\
\text { equations) }\end{array}$ & & & \\
\hline [73] & & Steady CFD & & \\
\hline$[74]$ & $\begin{array}{l}\text { 3D FEM: beam, } \\
\text { shell and solid } \\
\text { elements }\end{array}$ & Steady CFD & & \\
\hline [85] & $\begin{array}{l}\text { 3D FEM: beam and } \\
\text { shell elements }\end{array}$ & DLM & & \\
\hline
\end{tabular}




\begin{tabular}{|c|c|c|c|c|}
\hline [100] & $\begin{array}{l}\text { Analytical } \\
\text { (Lagrange’s } \\
\text { equations) }\end{array}$ & $\begin{array}{l}\text { Analytical (unsteady } \\
\text { strip theory) }\end{array}$ & & \\
\hline [105] & & VLM & Pole placement & \\
\hline [106] & $\begin{array}{l}\text { 3D FEM: beam } \\
\text { elements }\end{array}$ & $\begin{array}{l}\text { Analytical (unsteady } \\
\text { strip theory) }\end{array}$ & $\begin{array}{l}\text { Pseudo-inverse \& } \\
\text { quadratic } \\
\text { programming }\end{array}$ & \\
\hline [111] & $\begin{array}{l}\text { Rigid multi-body } \\
\text { model }\end{array}$ & & $\begin{array}{l}\text { Backstepping \& } \\
\text { desired angular } \\
\text { acceleration } \\
\text { function }\end{array}$ & \\
\hline [115] & $\begin{array}{l}\text { Symmetric laminate } \\
\text { plate theory }\end{array}$ & & & SIMP method \\
\hline [122] & $\begin{array}{l}\text { 3D FEM: beam and } \\
\text { shell elements }\end{array}$ & Steady CFD & & $\begin{array}{l}\text { Multi-objective } \\
\text { genetic algorithm }\end{array}$ \\
\hline
\end{tabular}


Table 4: Aerodynamic methods applied to morphing wings

\begin{tabular}{|c|c|c|c|}
\hline \multicolumn{3}{|c|}{ Aerodynamics method } & References \\
\hline \multirow{2}{*}{ Steady } & \multicolumn{2}{|c|}{ Linear methods } & [39], [69],[70], [71] \\
\hline & \multicolumn{2}{|l|}{ Nonlinear method } & [72], [74], [75] \\
\hline \multirow{4}{*}{ Unsteady } & \multicolumn{2}{|c|}{ Analytical methods } & [77], [78], [79] \\
\hline & \multirow{2}{*}{ Linear methods } & Unsteady vortex lattice method & [83],[84] \\
\hline & & Doublet-lattice method & {$[85],[86],[87]$} \\
\hline & \multicolumn{2}{|l|}{ CFD method } & [88], [89], [90], [91] \\
\hline
\end{tabular}




\section{References}

[1] Min Z, Kien VK, Richard LJY. Aircraft morphing wing concepts with radical geometry change. Journal Part A Civil \& Structural Engineering. 2010; 3:188-95.

[2] Sofla AYN, Meguid SA, Tan KT, Yeo WK. Shape morphing of aircraft wing: Status and challenges. Mater Design. 2010; 31: 1284-92.

[3] Vasista S, Tong L, Wong KC. Realization of morphing wings: A multidisciplinary challenge. J Aircraft. 2012; 49:1128.

[4] Lachenal X, Daynes S, Weaver PM. Review of morphing concepts and materials for wind turbine blade applications. Wind Energy. 2013; 16:283-307.

[5] Daynes S, Weaver PM. Review of shape-morphing automobile structures: Concepts and outlook. Proceedings of the Institution of Mechanical Engineers Part D Journal of Automobile Engineering. 2013; 227:1603-22.

[6] Daynes S, Weaver PM. Stiffness tailoring using prestress in adaptive composite structures. Compos Struct. 2013; 106:282-7.

[7] Kuder IK, Arrieta AF, Raither WE, Ermanni P. Variable stiffness material and structural concepts for morphing applications. Prog Aerosp Sci. 2013; 63: 33-55.

[8] Barbarino S, Saavedra Flores EI, Ajaj RM, Dayyani I, Friswell MI. A review on shape memory alloys with applications to morphing aircraft. Smart Mater Struc. 2014;23:63001.

[9] Sinapius M, Monner HP, Kintscher M, Riemenschneider J. DLR's morphing wing activities within the European network. IUTAM. 2014; 10:416-26.

[10] Hu N, Burgueño R. Buckling-induced smart applications: recent advances and trends. Smart Mater Struc. $2015 ; 24$.

[11] Dayyani I, Shaw AD, Flores EIS, Friswell MI. The mechanics of composite corrugated structures: a review with applications in morphing aircraft. Compos Struct. 2015; 133:358-80.

[12] Sun J, Guan Q, Liu Y, Leng J. Morphing aircraft based on smart materials and structures: a state-of-the-art review. J Intel Mat Syst Str. 2016.

[13] Yin W, Liu J, Leng J. Deformation analysis of shape memory polymer for morphing wing skin under airflow. Frontiers of Mechanical Engineering. 2009; 4:447-9.

[14] Yin W, Chen Y. Design and analysis of adaptive honeycomb structure with pneumatic muscle fibers. Proceedings of SPIE. 2012; 8339:83390M.

[15] Yin WL. Stiffness requirement of flexible skin for variable trailing-edge camber wing. Sci China Technol Sc. 2010; 53:1077-81.

[16] Chen Y, Yin W, Liu Y, Leng J. Structural design and analysis of morphing skin embedded with pneumatic muscle fibers. Smart Mater Struc. 2011; 20:298-300.

[17] Monner, HP, Kintscher M, Lorkowski T. Storm s, Design of a smart droop-nose as leading-edge high-lift system for transportation aircraft, 50th AIAA/ASME/ASCE/AHS/ASC Structures, Structural Dynamics, and Materials Conference, 2009, Palm Springs, California.

[18] Kintscher, Markus und Monner, Hans Peter und Heintze, Olaf. Experimental testing of a smart leading-edge highlift device for commercial transportation aircraft. 27th International Congress of the Aeronautical Sciences, 2010, Nizza, Frankreich.

[19] Monner, Hans Peter und Riemenschneider, Johannes und Kintscher, Markus: Groundtest of a Composite Smart Droop-nose. 53rd AIAA/ASME/ASCE/AHS/ASC Structures, Structural Dynamics and Materials Conference 2012, Honolulu, Hawaii.

[20] Kintscher, Markus und Wiedemann, Martin und Monner, Hans Peter und Heintze, Olaf und Kühn, Timo. Design of a smart leading-edge device for low-speed wind tunnel tests in the European project SADE. International Journal of 
Structural Integrity, 2 (4): 383-405.

[21] Kintscher, Markus und Monner, Hans Peter und Kühn, T. und Wild, J. und Wiedemann, Martin: Low-speed wind tunnel test of a morphing leading-edge. AIDAA - Italian Association of Aeronautics and Astronautics XXII Conference, 2013, Neapel, Italen.

[22] Kirn J, Storm S, Kinematic Solution for a highly adaptive Droop-nose, ICAST2014: 25th International Conference on Adaptive Structures and Technologies, 2014, The Hague, The Netherlands.

[23] Storm S. Kirn J. Towards the industrial application of morphing aircraft wings - development of the actuation kinematics of a droop-nose, 7th ECCOMAS Thematic Conference on Smart Structures and Materials, 2015.

[24] Kintscher, Markus und Kirn, Johannes und Storm, Stefan und Peter, Fabian. Assessment of the SARISTU enhanced adaptive droop-nose. Smart Intelligent Aircraft Structures (SARISTU) Springer, 2016, 113-140.

[25] Geier, Sebastian und Kintscher, Markus und Wierach, Peter und Monner, Hans Peter und Wiedemann, Martin. Experimental and finite element analyses of multifunctional skins for morphing wing applications. Sensors and Smart Structures Technologies for Civil, Mechanical, and Aerospace Systems, 2016, Las Vegas, Nevada.

[26] Kintscher, Markus and Kirn, Johannes and Monner, Hans Peter. Ground Test of an enhanced adaptive droop nose device. VII European Congress on Computational Methods in Applied Sciences and Engineering, 2016, Crete Island, Greece.

[27] Vasista, Srinivas und Riemenschneider, Johannes und Monner, Hans Peter. Design and testing of a compliant mechanism-based demonstrator for a droop-nose morphing device. 23rd AIAA/AHS Adaptive Structures Conference, 2015, Kissimmee, Florida.

[28] Vasista, Srinivas und Monner, Hans Peter und Riemenschneider, Johannes und Van de Kamp, Bram. Novemor droop-nose adaptive morphing wingtip: a design synopsis. Workshop on skins for morphing, 2014, Braunschweig, Germany.

[29] Cheung, R.C.M. und Wales, C. und Cooper, J.E. und Vasista, Srinivas und Riemenschneider, Johannes und Van de Kamp, Bram und Monner, Hans Peter. Wind tunnel test of a morphing wingtip leading-edge. International Forum on Aeroelasticity and Structural Dynamics, 2015, Saint Petersburg, Russia.

[30] Monner H P. Realization of an optimized wing camber by using formvariable flap structures. Aerosp Sci Technol, 2001, 5(7): 445-455.

[31] Campanile LF, Sachau D. The Belt-Rib Concept: A structronic approach to variable camber, J Intel Mat Syst Str. 2000; 11: 215-224.

[32] Btoez RM, Popov AV, Courchesne S. New aeroelastic studies for a morphing wing. INCAS Bulletin. 2012; 4:1928.

[33] Popov AV, Labib M, Fays J, Botez RM. Closed-loop control simulations on a morphing wing. J Aircraft. 2008; 45:1794-803.

[34] Popov AV, Grigorie LT, Botez RM, Mamou M, Mébarki Y. closed-loop control validation of a morphing wing using wind tunnel tests. J Aircraft. 2010; 47:1309-17.

[35] Lucian G, Andrei P, Ruxandra MB. Control of actuation system based smart material actuators in a morphing wing experimental model. AIAA Atmospheric Flight Mechanics (AFM) Conference; 2013, Boston, MA.

[36] Lucian TG, Ruxandra MB. Control strategies for an experimental morphing wing model. AIAA Atmospheric Flight Mechanics Conference; 2014, Atlanta, GA.

[37] Grigorie T L, Botez R M, Popov A V. Design and experimental validation of a control system for a morphing wing. AIAA Atmospheric flight mechanics conference. 2012, Minneapolis, Minnesota.

[38] Popov AV, Grigorie TL, Botez RM, Mébarki Y, Mamou M. Modeling and testing of a morphing wing in open-loop architecture. J Aircraft. 2010; 47:917-23.

[39] Coutu D, Brailovski V, Terriault P, Mamou M, Mebarki Y. Aerostructural model for morphing laminar wing 
optimisation in a wind tunnel. J Aircraft. 2011; 48:66-76.

[40] Popov AV, Grigorie LT, Botez RM, Mamou M, Mébarki Y. Real time morphing wing optimisation validation using wind-tunnel tests. J Aircraft. 2010; 47:1346-55.

[41] Ajaj R M, Saavedra Flores E I, Friswell M I, et al Span morphing using the compliant spar. J Aerosp Eng , 2014, 28(4): 04014108.

[42] Vale J, Leite A, Lau F, Suleman A. Aero-structural optimisation and performance evaluation of a morphing wing with variable span and camber. J Intel Mat Syst Str. 2011; 22:1057-73.

[43] Vocke RD, Kothera CS, Woods BKS, Wereley NM. Development and testing of a span-extending morphing wing. J Intel Mat Syst Str. 2011; 22:879-90.

[44] Vocke RD, Kothera CS, Wereley NM. Development of a quasi-static span-extending blade tip for a morphing helicopter rotor. J Aircraft. 2015; 52:792-804.

[45] Tarabi A, Ghasemloo S, Mani M. Experimental investigation of a variable-span morphing wing model for an unmanned aerial vehicle. J Braz Soc Mech Sci. 2016; 38:1833-41.

[46] Ajaj RM, Friswell MI, Bourchak M, Harasani W. Span morphing using the GNATSpar wing. Aerosp Sci Technol. 2016; 53:38-46.

[47] Ajaj RM, Flores EIS, Friswell MI, Allegri G, Woods BKS, Isikveren AT, et al The Zigzag wingbox for a span morphing wing. Aerosp Sci Technol. 2013; 28:364-75.

[48] The RoboSwift Team. RoboSwift. http://www. roboswift.nl/

[49] Siddall R, Ancel A O, Kovač M. Wind and water tunnel testing of a morphing aquatic micro air vehicle. Interface Focus, 2017, 7(1): 20160085.

[50] Chen S, Yue K, Hu B, Guo R. Numerical simulation on the radar cross section of variable-sweep wing aircraft. Journal of Aerospace Technology and Management. 2015; 7:170-8.

[51] Xu L, Yang S, Mo B. Pitching dynamic response of variable sweep wing aircraft. Appl Mech Mat. 2012; 197:15963.

[52] Jesse E, Dijkstra J. Design study of a supersonic business jet with variable sweep wings. 27th International Congress of the Aeronautical Sciences. 2010, Acropolis Conference Centre, Nice.

[53] Jenett B, Calisch S, Cellucci D, et al Digital Morphing Wing: Active wing shaping concept using composite lattice-based cellular structures. Soft Robot, 2017, 4(1):33-48.

[54] Ahmed MR, Abdelrahman MM, ElBayoumi GM, Einomrossy MM. Optimal wing twist distribution for roll control of MAVs. Aeronaut J. 2011; 115:641-9.

[55] Ismail N I, Zulkifli A H, Abdullah M Z, et al Optimization of aerodynamic efficiency for twist morphing MAV wing. Chinese J Aeronaut, 2014, 27(3): 475-487.

[56] Vos R, Gurdal Z, Abdalla M. Mechanism for warp-controlled twist of a morphing wing. J Aircraft. 2010;47:450-7.

[57] Rodrigue H, Cho S, Han MW, Bhandari B, Shim JE, Ahn SH. Effect of twist morphing wing segment on aerodynamic performance of UAV. Journal of Mechanical Science and Technology. 2016; 30:229-36.

[58] Raither W, Heymanns M, Bergamini A, Ermanni P. Morphing wing structure with controllable twist based on adaptive bending-twist coupling. Smart Mat Struct. 2013; 22:65017-65031

[59] Lentink D, Müller UK, Stamhuis EJ, Kat RD, Gestel WV, Veldhuis LLM, et al How swifts control their glide performance with morphing wings. Nature. 2007; 446:1082-1085.

[60] Josh Mills, Rafic Ajaj. Flight Dynamics and control using folding wingtips: an experimental study. Aerosp, 2017, 4: $1-24$.

[61] Nan Ma, Xiaodong Zhou, Guangping He, et al, Design and analysis of a bat-like active morphing wing mechanism. 40th Mechanisms and Robotics Conference, 2016, Charlotte, North Carolina.

[62] Wang I, Dowell E H. Structural dynamics model of multisegmented folding wings: theory and experiment. J Aircraft, 
2011, 48(6):911-921.

[63] Luca M D, Mintchev S, Heitz G, et al Bioinspired morphing wings for extended flight envelope and roll control of small drones. Interface Focus, 2017, 7(1):20160092.

[64] Ermakova A, Dayyani I. Shape optimisation of composite corrugated morphing skins. Compos Part B-Eng, 2017, 115: 87-101.

[65] Shaw A D, Dayyani I, Friswell M I. Optimisation of composite corrugated skins for buckling in morphing aircraft. Compos Struct, 2015, 119:227-237.

[66] Wissa A, Calogero J, Wereley N, et al. Analytical model and stability analysis of the leading edge spar of a passively morphing ornithopter wing. Bioinspir biomim, 2015, 10(6): 065003.

[67] Arrieta A F, Bilgen O, Friswell M I, et al. Modelling and configuration control of wing-shaped bi-stable piezoelectric composites under aerodynamic loads. Aerosp Sci Technol, 2013, 29(1): 453-461.

[68] Ai Q, Weaver P M. Simplified analytical model for tapered sandwich beams using variable stiffness materials. J Sandw Struct Mat, 2017, 19(1): 3-25.

[69] Drela, M. XFOIL: An analysis and design system of low reynolds number aerofoils, Springer-Verlag, 1989. 54:1-12.

[70] Cody L, Kelly C, Shaaban A. Use of XFOIL in design of camber-controlled morphing UAVs. Comput Appl Eng Educ. 2012; 20:673-80.

[71] Woods B, Fincham J H S, Friswell M I. Aerodynamic modelling of the fish bone active camber morphing concept. RAeS Applied Aerodynamics Conference, 2014, Bristol, UK.

[72] Fincham J H S, Friswell M I. Aerodynamic optimisation of a camber morphing aerofoil. Aerosp Sci Technol, 2015, 43:245-255.

[73] Downsborough JD, Lai SJ, Bond IP, Jones DP. Aerodynamic study of corrugated skins for morphing wing applications. Aeronaut J. 2010; 114:237-44.

[74] Gabor OŞ, Koreanschi A, Botez RM, Mamou M, Mebarki Y. Numerical simulation and wind tunnel tests investigation and validation of a morphing wing-tip demonstrator aerodynamic performance. Aerosp Sci Technol. 2016; 53:136-53.

[75] Lyu Z, Martins J. Aerodynamic Shape optimisation of an adaptive morphing trailing-edge wing. J Aircraft. 2014.

[76] Peters DA, Hsieh MCA, Torrero A. A state-space airloads theory for flexible aerofoils. J Am Helicopter So. 2007; 52:329-42.

[77] Palacios R, Cesnik CE. Low-speed aeroelastic modelling of very flexible slender wings with deformable aerofoils.49th AIAA/ASME/ASCE/AHS/ASC Structures, Structural Dynamics, and Materials, 2008, Schaumburg, IL.

[78] Murua J, Palacios R, Peiró J. Camber effects in the dynamic aeroelasticity of compliant aerofoils. J Fluid Struct. 2010; 26:527-43.

[79] Berci M, Gaskell PH, Hewson RW, Toropov VV. A semi-analytical model for the combined aeroelastic behaviour and gust response of a flexible aerofoil. J Fluid Struct. 2013;38:3-21.

[80] Johnston CO, Mason WH, Han C. Unsteady thin aerofoil theory revisited for a general deforming aerofoil. J Mech Sci Technol. 2011;24:2451-60.

[81] Walker WP, Patil MJ. Unsteady aerodynamics of deformable thin aerofoils. J Aircraft. 2014;51:1673-80.

[82] Mohammadi-Amin M, Ghadiri B, Abdalla MM, Haddadpour H, Breuker RD. Continuous-time state-space unsteady aerodynamic modelling based on boundary element method. Eng Anal Bound Ele. 2012;36:789-98.

[83] Verstraete ML, Preidikman S, Roccia BA, Mook DT. A numerical model to study the nonlinear and unsteady aerodynamics of bioinspired morphing-wing concepts. Int J Micro Air Veh. 2015;7:327-45.

[84] Ghommem M, Hajj MR, Mook DT, Stanford BK, Beran PS, Snyder RD, et al Global optimisation of actively morphing flapping wings. J Fluid Struct. 2012;33:210-28. 
[85] Li D, Guo S, Xiang J. Modeling and nonlinear aeroelastic analysis of a wing with morphing trailing-edge. Proceedings of the Institution of Mechanical Engineers Part G J Aerosp Eng. 2013;227:619-631.

[86] $\mathrm{Hu}$ W, Yang Z, Gu Y. Aeroelastic study for folding wing during the morphing process. J Sound Vib, 2016, 365:216-229.

[87] $\mathrm{Hu} \mathrm{W,} \mathrm{Yang} \mathrm{Z,} \mathrm{Gu} \mathrm{Y,} \mathrm{et} \mathrm{al} \mathrm{The} \mathrm{nonlinear} \mathrm{aeroelastic} \mathrm{characteristics} \mathrm{of} \mathrm{a} \mathrm{folding} \mathrm{wing} \mathrm{with} \mathrm{cubic} \mathrm{stiffness.} \mathrm{J} \mathrm{Sound}$ Vib, 2017, 400:22-39.

[88] Zhang GQ, Yu SCM. Unsteady aerodynamics of a morphing tandem-wing unmanned aerial vehicle. J Aircraft. 2012; 49:1315-23.

[89] Selitrennik E, Karpel M, Levy Y. Computational aeroelastic simulation of rapidly morphing air vehicles. J Aircraft. 2012;49:1675-86.

[90] Liu D, Chen P, Zhang Z, Wang Z, Yang S, Lee D, et al Continuous dynamic simulation for morphing wing aeroelasticity. 50th AIAA/ASME/ASCE/AHS/ASC Structures, Structural Dynamics, and Materials Conference, 2009, Palm Springs, California.

[91] Liu K, Li D, Xiang J. Reduced-order modeling of unsteady aerodynamics of a flapping wing based on the Volterra theory. Results in Physics. 2017; 7:2451-7.

[92] Bilgen O, Flores E I S, Friswell M I. Optimization of surface-actuated piezocomposite variable-camber morphing wings. Smart Materials, Adaptive Structures and Intelligent Systems, 2011: 1-8.

[93] Attar PJ, Tang D, Dowell EH. Nonlinear aeroelastic study for folding wing structures. AIAA Journal. 2010;48:218795.

[94] Molinari G, Arrieta AF, Ermanni P. Planform, Aero-structural and flight control optimisation for tailless morphing aircraft. Proceedings of SPIE. 2015.

[95] Ismail NI, Zulkifli AH, Abdullah MZ, Basri MH, Abdullah NS. Computational aerodynamic analysis on perimeter reinforced (PR)-compliant wing. Chinese J Aeronaut. 2013; 26:1093-1105.

[96] Huang R, Qiu Z. Transient aeroelastic responses and flutter analysis of a variable-span wing during the morphing process. Chinese J Aeronaut. 2013;26:1430-1438.

[97] Huang R, Qiu ZP, Wang XJ. Continuum aeroelastic model and flutter analysis for a variable-span morphing wing. Appl Mech Mat.2013. 1136-1143.

[98] Castrichini A, Hodigere Siddaramaiah V, Calderon DE, Cooper JE, Wilson T, Lemmens Y. Nonlinear folding wing tips for gust loads alleviation. J Aircraft. 2016; 53:1391-1399.

[99] Shrestha P, Jeong MS, Lee I, Bae JS, Koo KN. Flutter characteristics of a morphing flight vehicle with varying inboard and outboard folding angles. Int J Aeronaut Space. 2013;14:133-139.

[100] Wang I, Gibbs SC, Dowell EH. Aeroelastic model of multisegmented folding wings: theory and experiment. J Aircraft. 2012;49:911-921.

[101] Pecora R, Magnifico M, Amoroso F, Monaco E. Multi-parametric flutter analysis of a morphing wing trailingedge. Aeronaut J. 2014; 118:1063-1078.

[102] Dimino I, Concilio A, Schueller M, Gratias A. An adaptive control system for wing te shape control. Proceedings of SPIE. Bellingham: SPIE - The International Society for Optical Engineering; 2013.

[103] Shi RQ, Song JM. Dynamics and control for an in-plane morphing wing. Aircr Eng Aerosp Technol. 2013;85:2431.

[104] Wang T, Dong CY, Wang Q. Finite-time boundedness control of morphing aircraft based on switched systems approach. International Journal for Light and Electron Optics. 2015;126:4436-45.

[105] Li DC, Guo SJ, Aburass TO, Yang DQ, Xiang JW. Active control design for an unmanned air vehicle with a morphing wing. Aircr Eng Aerosp Tec. 2016;88:168-77.

[106] Wang ZJ, Sun YD, Yang DQ, Guo SJ. Active control using control allocation for uavs with seamless morphing 
wing. Proceedings of SPIE. Bellingham: SPIE - The International Society for Optical Engineering; 2012.

[107] Tong L, Ji H. Multi-body dynamic modelling and flight control for an asymmetric variable sweep morphing UAV. Aeronaut J. 2014;118:683-706.

[108] Liu CS, Zhang SJ. Novel robust control framework for morphing aircraft. J Syst Eng Electron. 2013;24:281-7.

[109] He Z, Yin M, Lu YP. Tensor product model-based control of morphing aircraft in transition process. Proceedings of the Institution of Mechanical Engineers Part G J Aerosp Eng. 2016;230:378-91.

[110] Zhang J, Wu ST, Ieee. Dynamic modeling and control for a morphing aircraft. Chinese Control and Decision Conference, 2014, New York.

[111] Colorado J, Barrientos A, Rossi C, Parra C. Inertial attitude control of a bat-like morphing-wing air vehicle. Bioinspir biomim. 2013;8:18.

[112] Yue T, Wang LX, Ai JQ. Gain self-scheduled H-infinity control for morphing aircraft in the wing transition process based on an LPV model. Chinese J Aeronaut. 2013;26:909-17.

[113] Pecora R, Amoroso F, Lecce L. Effectiveness of wing twist morphing in roll control. J Aircraft. 2012;49:166674.

[114] Vasista S, Tong L. Topology optimisation via the moving iso-surface threshold method: implementation and application. Aeronaut J. 2014;118:315-42.

[115] Tong X, Ge W, Sun C, Liu X. Topology optimisation of compliant adaptive wing leading-edge with composite materials. Chinese J Aeronaut. 2014;27:1488-94.

[116] Sleesongsom S, Bureerat S, Tai K. Aircraft morphing wing design by using partial topology optimisation. Struct Multidiscip O. 2013;48:1109-28.

[117] Lyu Z, Martins JRRA. Aerodynamic shape optimisation of an adaptive morphing trailing-edge wing. J Aircraft. 2015;52:1951-70.

[118] Stanford BK, Beran PS. Analytical sensitivity analysis of an unsteady vortex-lattice method for flapping-wing optimisation. J Aircraft. 2010;47:647-62.

[119] Garg N, Kenway GKW, Lyu Z, Martins JRRA, Young YL. High-fidelity hydrodynamic shape optimisation of a 3-D hydrofoil. J Ship Res. 2015;59:209-26.

[120] De Gaspari A, Ricci S. A two-level approach for the optimal design of morphing wings based on compliant structures. J Intel Mat Syst Str. 2011;22:1091-111.

[121] Molinari G, Arrieta AF, Ermanni P. Aero-structural optimisation of three-dimensional adaptive wings with embedded smart actuators. AIAA J. 2014; 52:1940-51.

[122] Vasista S, De Gaspari A, Ricci S, Riemenschneider J, Monner HP, van de Kamp B. Compliant structures-based wing and wingtip morphing devices. Aircr Eng Aerosp Tec. 2016; 88:311-30.

[123] Zhao K, Schmiedeler JP, Murray AP. Design of planar, shape-changing rigid-body mechanisms for morphing aircraft wings. J Mech Robot. 2012; 4.

[124] Koreanschi A, Sugar-Gabor O, Botez RM. Drag optimisation of a wing equipped with a morphing upper surface. Aeronaut J. 2016; 120:473-93.

[125] De Gaspari A, Ricci S. Knowledge-based shape optimisation of morphing wing for more efficient aircraft. International J Aerosp Eng . 2015.

[126] Namgoong H, Crossley WA, Lyrintzis AS. Morphing aerofoil design for minimum drag and actuation energy including aerodynamic work. J Aircraft. 2012; 49:981-90.

[127] Sleesongsom S, Bureerat S. Morphing wing structural optimisation using opposite-based population-based incremental learning and multigrid ground elements. Math Probl Eng. 2015.

[128] Botez RM, Koreanschi A, Sugar-Gabor O. Numerical and experimental validation of a morphed wing geometry using Price-Paidoussis wind-tunnel testing. Aeronaut J. 2016; 120:757-95. 
[129] Wu J, Yan S, Gu Y. On stability optimisation of the deployable bistable compliant structures mounted in the morphing skin: Method and implementation. P I Mech Eng Part C-J Mec. 2015; 229:943-56.

[130] Olympio KR, Gandhi F. Optimal cellular core topologies for one-dimensional morphing aircraft structures. J Mech Design. 2012; 134.

[131] Bharti S, Frecker M, Lesieutre G. Optimal morphing-wing design using parallel nondominated sorting genetic algorithm II. AIAA J. 2009; 47:1627-34.

[132] Zhao K, Schmiedeler JP. Using rigid-body mechanism topologies to design shape-changing compliant mechanisms. J Mech Robot. 2016; 8:011014.

[133] Li L, Liu Z, Wen N. Dynamic modeling for a variable-span and variable-sweep unmanned aerial vehicle. IEEE Guidance, Navigation and Control Conference, 2017:1305-1310.

[134] Pankonien A M, Inman D J. Spanwise morphing trailing edge on a finite wing. SPIE Smart Structures and Materials+ Nondestructive Evaluation and Health Monitoring. International Society for Optics and Photonics, 2015.

[135] Inman DJ. Experimental testing of spanwise morphing trailing-edge concept. The International Society for Optical Engineering. 2013: 868815.

[136] Pendleton E, Back to the Future-How Active Aeroelastic Wings are a Return to Aviation's Beginnings and a Small Step to Future Bird-Like Wings, RTO AVT Symposium on Active Control Technology for Enhanced Performance Operational Capabilities of Military Aircraft, Land Vehicles and Sea Vehicles, Braunschweig, Germany, 2000.

[137] Parker H F. The Parker Variable Camber Wing, NACA, Rept. 77, 1920.

[138] Powers S G, Webb L D, Friend E L, and Lokos W A. Flight Test Results from a Supercritical Mission Adaptive Wing with Smooth Variable Camber, NASA, TM-4415, Nov. 1992.

[139] Jardine A P, Bartley-Cho J, and Flanagan J. Improved Design and Performance of the SMA Torque Tube for the DARPA Smart Wing Program, Proceedings of SPIE, 1999, pp. 260-269.

[140] Pendleton E W, Bessette D, Field P B, et al Active aeroelastic wing flight research program: technical program and model analytical development. J Aircraft, 2000, 37(4): 554-561.

[141] Scherer L B, Martin C A, Sanders B P, et al DARPA/AFRL Smart Wing Phase 2 wind tunnel test results. SPIE's 9th Annual International Symposium on Smart Structures and Materials. International Society for Optics and Photonics, 2002: 64-75.

[142] Lagoudas D C, Garner L J, Rediniotis O K, et al Modeling and experiments of the hysteretic response of an active hydrofoil actuated by SMA line actuators. Proceedings of the NATO Advanced Research Workshop on Smart Structures: Require-ments and Potential Applications in Mechanical and Civil Engineering, Kluwer Academic, Dordrecht, The Netherlands, 1999, pp. 153-162.

[143] Heyland D, Rosemann H, Sachau D, et al The adaptive wing project (DLR): Survey on targets and recent results from active/adaptive structures viewpoint. Proceedings of the Tenth International Conference on Adaptive Structures and Tech-nologies, Technomic Publishing, Lancaster, PA, 1999, pp. 178-185.

[144] Kota S, Osborn R, Ervin G, et al Mission adaptive compliant wing-design, fabrication and flight test. RTO Applied Vehicle Technology Panel (AVT) Symposium, Evora, Portugal, 20-24 April 2009.

[145] Love M H, Zink P S, Stroud R L, et al Impact of Actuation Concepts on Morphing Aircraft Structures. 45th AIAA/ASME/ASCE/AHS/ASC Structures, Structural Dynamics and Materials Conference, Palm Springs, CA, 2004.

[146] Bowman J, Sanders B, Cannon B, et al Development of next generation morphing aircraft structures. 48th AIAA/ASME/ASCE/AHS/AC Structures, Structural Dynamics and Materials Conference, Honolulu, 2007.

[147] Strelec J K, Lagoudas D C, Khan M A, et al Design and implementation of a shape memory alloy actuated reconfigurable aerofoil. J Intel Mat Syst Str, 2003, 14(4-5): 257-273. 
[148] Wiggins III L D. Structural Design and Analysis of a Kinematic Mechanism for a Morphing Hyper-Elliptic Cambered Span (HECS) Wing. M.S. Thesis, Virginia Polytechnic Institute and State University, Blacksburg, VA, 2003.

[149] Poonsong P. Design and Analysis of Multi-Section Variable Camber Wing. M.S. Thesis, University of Maryland, College Park, MD, 2004.

[150] Abdulrahim M, Lind R. Flight testing and response characteristics of a variable gull-wing morphing aircraft. AIAA Guidance, Navigation, and Control Conference and Exhibit, Providence, RI, 2004.

[151] Mason W H, Robertshaw H, Inman D J. Recent experiments in aerospace and design engineering education. 42nd AIAA Aerospace Sciences Meeting and Exhibit, Reno, NV, 2004.

[152] Jacob J D, Simpson A, Smith S. Design and flight testing of inflatable wings with wing warping. SAE Technical Paper, 2005.

[153] Manzo J E. Analysis and Design of a Hyper-Elliptical Cambered Span Morphing Aircraft Wing. M.S. Thesis, Cornell University, Ithaca, NY, 2006.

[154] Samuel J B, Pines D. Design and testing of a pneumatic telescopic wing for unmanned aerial vehicles. J Aircraft, 2007, 44(4): 1088.

[155] Supekar A H. Design, Analysis and Development of a Morphable Wing Structure for Unmanned Aerial Vehicle Performance Augmentation,” M.S. Thesis, University of Texas at Arlington, Arlington, TX, 2007.

[156] Diaconu C G, Weaver P M, Mattioni F. Concepts for morphing aerofoil sections using bi-stable laminated composite structures. Thin Wall Struct, 2008, 46(6): 689-701.

[157] Ursache $\mathrm{N} \mathrm{M}$, Melin T, Isikveren A $\mathrm{T}$, et al Technology integration for active poly-morphing winglets development. ASME Conference on Smart Materials, Adaptive Structures and Intelligent Systems. 2008.

[158] Icardi U, Ferrero L. Preliminary study of an adaptive wing with shape memory alloy torsion actuators. Mater Design, 2009, 30(10): 4200-4210.

[159] Joshi S P, Tidwell Z, Crossley W A, Ramakrishnan S. Comparison of morphing wing strategies based upon aircraft performance impacts. 45th AIAA/ASME/ASCE/AHS/ASC Structures, Structural Dynamics \& Materials Conference, California, 2004.

[160] Dayyani I, Friswell MI, Ziaei-Rad S, Flores ES. Equivalent models of composite corrugated cores with elastomeric coatings for morphing structures. Composite Structures. 2013 Oct 1;104:281-92.

[161] Dayyani I, Friswell MI, Flores EI. A general super element for a curved beam. International Journal of Solids and Structures. 2014 Aug 15;51(17):2931-9.

[162] Wickenheiser A, Garcia E. Aerodynamic modeling of morphing wings using an extended lifting-line analysis. Journal of Aircraft. 2007;44(1):10-6.

[163] Spadoni A, Ruzzene M. Static aeroelastic response of chiral-core airfoils. Journal of intelligent material Systems and Structures. 2007;18(10):1067-75. 